\title{
The Influence of Self-Reported Family Functioning on Depression Symptom Severity and Psychological Well-Being in Treatment- Seeking Older Adults
}

\author{
Patricia M. Bamonti \\ West Virginia University
}

Follow this and additional works at: https://researchrepository.wvu.edu/etd

\section{Recommended Citation}

Bamonti, Patricia M., "The Influence of Self-Reported Family Functioning on Depression Symptom Severity and Psychological Well-Being in Treatment-Seeking Older Adults" (2012). Graduate Theses, Dissertations, and Problem Reports. 3542.

https://researchrepository.wvu.edu/etd/3542

This Thesis is protected by copyright and/or related rights. It has been brought to you by the The Research Repository @ WVU with permission from the rights-holder(s). You are free to use this Thesis in any way that is permitted by the copyright and related rights legislation that applies to your use. For other uses you must obtain permission from the rights-holder(s) directly, unless additional rights are indicated by a Creative Commons license in the record and/ or on the work itself. This Thesis has been accepted for inclusion in WVU Graduate Theses, Dissertations, and Problem Reports collection by an authorized administrator of The Research Repository @ WVU. For more information, please contact researchrepository@mail.wvu.edu. 
The Influence of Self-Reported Family Functioning on Depression Symptom Severity and Psychological Well-Being in Treatment-Seeking Older Adults

Patricia M. Bamonti

\author{
Thesis submitted to the \\ Eberly College of Arts and Sciences at \\ West Virginia University \\ in partial fulfillment of the requirements \\ for the degree for the degree of
}

Master of Science

in

Psychology

\begin{abstract}
Amy Fiske, Ph.D., CBSM
Barry Edelstein, Ph.D.

Aaron Metzger, Ph.D.
\end{abstract}

Department of Psychology
Morgantown, West Virginia
2012

Keywords: Late-life depression; psychological well-being; perceived criticism; emotional involvement 


\section{ABSTRACT \\ The Influence of Self-Reported Family Functioning on Depression Symptom Severity and Psychological Well-Being in Treatment-Seeking Older Adults}

\section{Patricia M. Bamonti}

Among treatment-seeking older adults, positive social ties are related to depression outcomes prospectively. Less is known regarding the role of negative social ties in relation to depression and well-being outcomes among patients in treatment. The current study adds to this literature through the cross-sectional and prospective examination of patients' appraisal of family members perceived criticism in relation to self-reported depressive symptom severity and psychological well-being In addition, potential moderators of these relations were examined, including personality variables (Neuroticism and Conscientiousness), cognitive functioning, and living status. adults 60 years of age and older newly ( $<1$ month after intake session) receiving treatment for depressive or anxious symptomatology at a university-affiliated outpatient clinic as part of an on-going study that assessed depression and decision-making in late life. Results demonstrated that individuals with increased perceived criticism also had greater depressive symptom severity, at least measured at one point in time. Perceived criticism failed to predict change in depression symptom severity in the prospective analyses. Similarly, perceived criticism was associated with lower psychological well-being in the cross-sectional analyses; however, perceived criticism failed to predict change in psychological well-being in prospective analyses. No significant interactions were found with perceived criticism, suggesting at least in the current study, personality variables, cognitive functioning, and living status did not qualify the relation between perceived criticism and depression symptom severity or change in depression symptom severity over time. EI was not significantly associated with depression symptom severity and psychological well-being cross-sectionally and prospectively, after controlling for perceived criticism and perceived social support from family. Implications, limitations, and future directions are discussed. 


\section{Table of Contents}

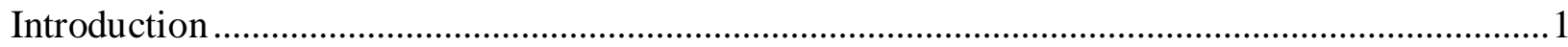

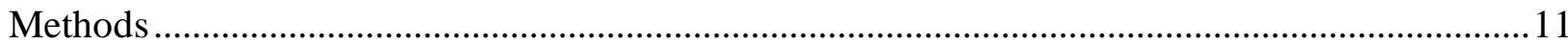

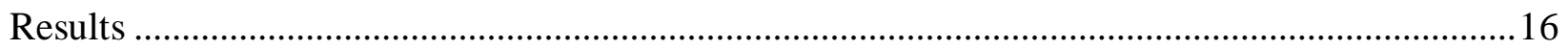

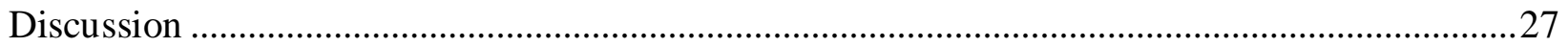

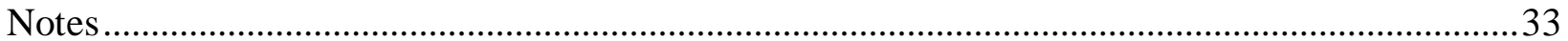

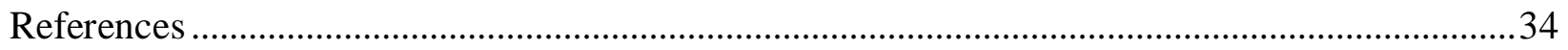

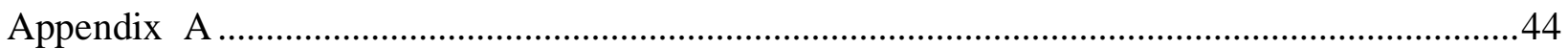

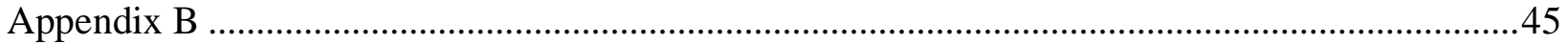

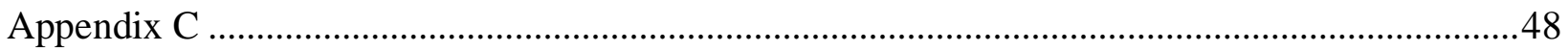

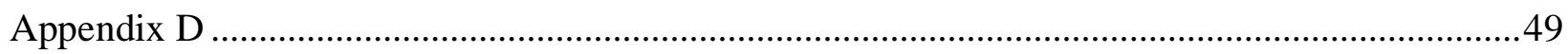

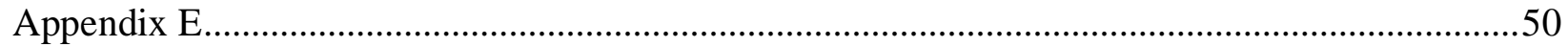

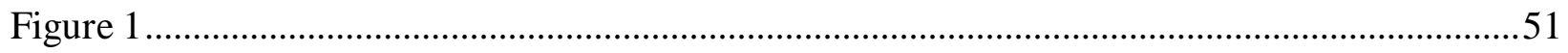

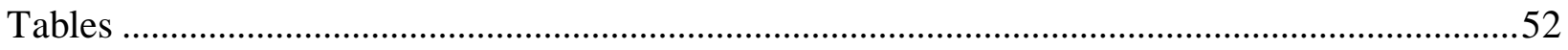




\section{Introduction}

Over the past several decades attention to the need for adequate detection and treatment of depression in late life has grown. Public awareness has been fueled by a growing body of research demonstrating a multitude of negative outcomes associated with the disease. Older adults suffering from depression are more likely to experience functional impairments (Callahan et al., 1998), increased medical burden (Alexopoulos al., 2002; Luber et al., 2000; Luber et al., 2001), greater likelihood of death from natural causes (Bruce et al., 1994; Penninx et al., 1999, 2001), and death by suicide (Conwell et al., 1996) compared to older adults without depression. The natural course of late life depression has been shown to be dire. Beekman et al. (2002) examined late life depression in community-dwelling older adults over a six year period. Out of a sample of 277 older adults with clinically significant depressive symptoms (baseline CES-D $\geq$ 16), only a minority (23\%) experienced full remission of depression symptoms. For the majority of depressed older adults, the course of illness fluctuated (44\%) or was chronic (32\%), and both groups were found to suffer from greater functional impairment and decreased quality of life compared to older adults in remission. Fortunately, the detection of late life depression has improved (Crystal, Sambamoorthi, Walkup, \& Akincigil, 2003), effective treatments exist (Pinquart, Duberstein, \& Lyness, 2006), and a greater percentage of older adults are receiving outpatient treatment than ever before (Marcus \& Olfson, 2010).

Although the rates of detection and treatment for late life depression have risen, little is known about factors associated with change in depression symptom severity in treatmentseeking older adults. Dew et al. (1997) explored trajectories of treatment response in older adults receiving standardized treatment for major depression. One factor that distinguished mixed or 
partial responders from individuals who made rapid/sustained improvement and nonresponders was low social support (Dew et al., 1997). This finding is consistent with the well-documented relation between social support and depression in late life (George, Blazer, Hughes, \& Fowler, 1989; Krause, 1986; Russel et al., 1991; Thompson \& Heller, 1990; Wallsten, Tweed, Blazer, \& George, 1999).

In particular, subjective social support has been shown to be most strongly correlated with depression in late life compared to other types of social support (e.g. social network size/composition, frequency of interaction, etc.), pointing to the salience of an individual's perception of support. Longitudinal studies examining treatment outcomes of older adults with depression provide additional evidence of the association between subjective social support and depression. For example, George et al. (1989) found that subjective social support predicted depressive symptoms 6-32 months following inpatient hospitalization for depression in middleaged and older adults. Further, subjective social support has been shown to predict depression in treatment seeking older adults as far out as 64 months following an initial interview, controlling for age, gender, Mini-Mental State Exam score and education (Steffen et al. 2008). Research in community-dwelling older adults has shown similar relations between subjective social support and depression (Russell \& Cutrona, 1991).

In addition to predicting depression in older adults, perceived social support has also been shown to be positively associated with indices of well-being, such as satisfaction in life (Uchino, Holt-Lunstad, Smith \& Bloor, 2004; Uchino, Holt-Lunstad, Uno, \& Flinders, 2001), quality in life (Finch, Okun, Barrera, Zautra, \& Reich, 1989), and psychological well-being (Thompson \& Heller, 1990). These findings suggest that social support is not only important for depressive symptoms, but also influences positive aspects of an individual's emotional health. 
Theorists have proposed that negative social support has greater influence on well-being than the actual presence of support (Coyne \& Bolgar, 1990). There appears to be evidence for this claim (Finch et al., 1989; Fiore, Becker, \& Coppel, 1983; Franks, Rook, 1984; Shields, Cambell, McDaneil, Harp \& Botelho, 1992; Kiecolt-Glaser et al., 1997; Umberson, 1992; Weissman, 1987). For example, Finch et al (1989) examined the association between positive and negative social ties in community-dwelling older adults. Negative ties were found to be associated with lower self-reported quality of life scores and increased distress scores, even after controlling for the influence of participant's demographics (age, income, gender), personality (Neuroticism and Extraversion), and presence of positive ties. Another study found that upsetting social interactions reported by spousal-caregivers of Alzheimer's patients were associated with greater depressive symptoms in spouses. In contrast, endorsement of helpful social exchanges was found to be unrelated to caregiver depressive symptoms (Fiore et al., 1983). Additional evidence of the detrimental influence of negative social relations has been demonstrated in intergenerational studies that examined the effect of older adult parent/adult child relationship qualities on parental well-being. Similar to the findings presented above, Umberson (1991) found that relationship strain in parent-child dyads was associated with greater parental depression symptoms and lower parental satisfaction in life. No significant associations were found for the frequency of parent/child interactions or parental ratings of support received from their children with parental depression symptoms or parental satisfaction in life. Lastly, epidemiological studies of prevalence rates of depression have offered additional support for the idea that negative social exchanges may be especially detrimental to well-being (Blazer, Hughes, \& George, 1987; Weissman, 1987). Weissman (1987) found that rates of major depression in the U.S. are lower for married individuals compared to single or separated/divorced individuals. 
Interestingly, however, rates were found to increase substantially ( 25-fold increase) for married individuals who reported not getting along with their spouse.

Although numerous studies have found evidence demonstrating a positive association between negative social relations and depression symptoms, the translation of this line of research to clinical populations has been limited to an examination of positive aspects of relationships only. Fortunately, a slightly different, but complimentary body of research exists that bridges the gap between nonclinical and clinical research-family therapy research.

Studies examining social interactions within the family have traditionally been interested in capturing a sample of family functioning that could then be used to base predictions regarding future psychological outcomes (e.g. psychiatric symptoms) of a particular family member, typically a clinical patient. One influential construct tapping family dynamics is expressed emotion. Expressed emotion was first conceptualized through observational studies of the family environment of schizophrenic patients returning home after inpatient treatment. Findings from these initial studies found that patients returning to families marked by critical, hostile, and/or emotionally overinvolved ("enmeshed") relations relapsed at higher rates compared to families not characterized by these features (Brown, Birley, \& Wing, 1972; Vaughn \& Leff, 1976). The cluster of hostile/critical and emotionally overinvolved relations was termed expressed emotion (Brown, Birley, \& Wing, 1972). The measurement of expressed emotion has traditionally involved a videotaped semi-structured interview with a family member of the participant, which is coded based on the number of critical/hostile and/or emotionally overinvolved comments. Analytic approaches have typically lumped patients into either high or low expressed emotion groups, which served as the predictor variable in the examination of treatment outcomes.

Research studies utilizing such an approach have found that expressed emotion predicts 
relapse in patients with schizophrenia (Leff \& Vaughn, 1981; Vaughn \& Leff, 1976) and patients with depression (Hooley, Orely, \& Teasedale, 1986; Okasha, El Akabawi, Snyder, \& Wilson,). Rates of nonremittance of depression symptoms following outpatient treatment have been shown to be higher in participants belonging to families high in criticism compared to individuals belonging to families low in criticism (Uehera, Yokoyama, Goto, \& Ihha, 1996). Additionally, assessment of the patient's appraisal of the family environment (vs. interviewing the spouse or significant other) appears to tap into a unique aspect of family functioning predictive of depression outcomes. For example, Hooley \& Teasdale (1989) found perceived criticism was associated with relapse nine months following inpatient treatment for unipolar depression, when controlling for expressed emotion and marital distress.

Shields, Frank, Harp, McDaniel, \& Campbell (1992) developed a self-report measure to assess, from the participant's perspective, family criticism and emotional involvement in the family context. The Family Emotional Involvement and Criticism Scale (FEICS) consists of two subscales, perceived criticism (PC) and emotional involvement (EI). The subscales are differentiated from the construct of expressed emotion by the perspective in which the constructs are assessed, namely, from the patient's view. Also, emotional overinvolvment was replaced with emotional involvement in order to eliminate the value judgment associated with the original wording (Shields et al., 1992).

Research studies with young and middle-aged adults have found PC to be positively correlated with depression and anxiety (Shields et al., 1992; Shields et al., 1994). However, emotional involvement has been shown to be negatively related to PC, suggesting that EI taps healthy closeness Further, EI has also been found to be nonsignificantly or negatively associated with depression and anxiety, suggesting that EI is characterized by positive closeness. 
Interestingly, when shared covariance with PC is partialled out, EI is positively associated with depression and anxiety. The Authors' conclude that this finding suggests that once covariance with PC is partialled out, elements of extreme, maladaptive closeness remain (Shields et al., 1992; Shields et al., 1994). In addition, partial correlations revealed that once PC and social support measures were partialled out, EI was positively correlated with both depression and anxiety. This finding points to the need to control for PC and measures of social support, when examining the relation between EI and outcome variables, such as depression and psychological well-being.

Further evidence is found for the need to examine negative aspects of social ties in a study by Franks et al. (1992), who found that the relationship between low social support and depressive symptoms in a sample of family practice patients was no longer significant after EI and PC were entered into the regression equation. It is possible that EI and PC are picking up on negative aspects of social support proposed to be most salient in terms of depression outcomes compared to positive aspects of social support. This idea is consistent with other findings demonstrating an independent association between perceived criticism and depression diagnosis and depression symptom severity in older adult primary care patients (Seaburn, Lynness, Eberly, \& King, 2005).

Self-reported family functioning by the identified patient member of the family has been shown to vary depending on certain individual characteristics. For instance, one study examined the association between psychiatric status (e.g. depression course, current Axis I and II diagnoses) and personality traits (e.g. Neuroticism, Conscientiousness, etc.) on self-reported family functioning (measured dichotomously: functional/dysfunctional; Miller et al., 2000). Using a backward regression model, Miller et al. (2000) found that three significant variables 
accounted for $31 \%$ of the variance in self-reported family functioning, including patient's Axis II symptoms, lower patient Conscientiousness and informant psychological distress. In another study, Miller et al. (1992) examined patient characteristics that were able to differentiate depressed adults belonging to a functional or dysfunctional family based on agreement of both an observer-rated and subjective measure of family functioning. The only characteristic that differentiated between the two groups was patient Neuroticism. These findings demonstrate that self-reported and observer-rated measures of family functioning are associated with patient personality; however, they may also point to the possibility that the influence of self-reported family functioning on treatment outcomes, such as depression symptoms, may differ based on the patient's personality.

\section{Purpose \& Hypotheses}

Previous research has demonstrated an association between PC, EI, and depressive symptoms in older adult primary care patients (Seaburn et al., 2005) however, there has yet to be an examination of the relations these constructs have with depression symptom severity and psychological well-being in older adults seeking mental health treatment. In addition, previous research on the relation between PC, EI and depression symptoms has been limited to crosssectional designs. Prospective studies are needed to examine whether PC and EI predict depression symptom severity over time, as well as the association with psychological well-being, which may also be associated with perceptions of family functioning (Thompson \& Heller, 1990). PC has consistently been shown to be associated with greater depression symptoms. In contrast, EI has been found to be negatively associated with depression, but when PC and social support have been controlled in analyses, EI has been found to be associated with greater 
depression, suggesting that once PC and social support are controlled for, EI may be tapping negative aspects of family functioning (Shields et al., 1992; Shields et al., 1994).

In addition, the examination of moderator variables that may interact with PC and EI in the prediction of depression symptom severity and psychological well-being have never been explored, even though patient characteristics, such as personality, have been shown to be related to family functioning (Miller, McDermitt, Gordon, Keitner, Ryan, \& Norman, 2000; Nomura et al., 2005).

Further, depression symptoms in late life may be further exacerbated by cognitive functioning difficulties. Perceived family criticism may differentially influence depressive symptom severity in patients experiencing greater cognitive functioning difficulties, because of feelings of dependency, frustration, and enhanced sensitivity that may emerge from the recognition of cognitive challenges. These ideas are exploratory in nature, but worth investigating.

Moreover, living status may influence how PC and EI relate to depressive symptom severity and psychological well-being. For instance, older adults who live with a spouse or other family members experience greater proximity and daily contact with family members compared to older adults who live alone. The nature of the relationship may be different between older adults with greater proximity to family members compared to older adults who live alone and have less direct contact with family, which could influence the relation between perceived criticism and depressive symptom severity and psychological well-being.

Lastly, past studies have not captured the specific relationship about which the participant is responding (e.g. spouse, sibling, etc.). Perceived criticism may be reflective of a negative lens, 
in which the current family climate is viewed in general, or it may also represent tension with a specific family member-which could inform treatment efforts. The current study explored descriptively the specific family members endorsed by patients while completing the FEICS.

The current study used a prospective design to examine how PC and EI were related to depression symptom severity and psychological well-being in older adults newly initiating mental health treatment (psychotherapy, pharmacotherapy, or a combination) for depression, anxiety, or adjustment disorder.

The first aim of the study was to examine the association between PC, EI and depression symptom severity, and PC, EI, and psychological well-being cross-sectionally $(<1$ month after intake session) and prospectively (6 months after treatment initiation) in older adult outpatients. It was predicted that PC and EI would be associated with depression symptom severity and psychological well-being cross-sectionally. In addition, it was predicted that baseline PC would predict greater depression symptom severity and lower psychological well-being in older adults six months after beginning treatment, after controlling for age and depression symptom severity at baseline. Based on previous research, which has found EI to be positively associated with depression, once PC and social support are controlled for (Shields et al., 1994), it was predicted that EI would be associated with greater depression symptom severity and lower psychological well-being, once PC and perceived social support were controlled for.

Previous research has demonstrated that lower self-reported patient conscientiousness predicts unhealthier self-reported family functioning. In addition, patient Neuroticism has been shown to differentiate depressed patients belonging to functional compared to dysfunctional families. Given these findings pointing to the importance of patient personality in predicting 
family functioning, the second aim of the study was to examine whether patient Neuroticism and Conscientiousness moderate the relation between PC and depression symptom severity crosssectionally and prospectively. It was predicted that the association between PC and depressive symptom severity would be qualified by patient's Neuroticism and Conscientiousness. In particular, given that individuals high in Neuroticism are characterized by an increased tendency to experience negative affect (Costa \& McCrae, 1992, p.14), it was predicted that the relation between perceived criticism and depressive symptom severity would be amplified in participants high in Neuroticism. Moreover, individuals who are low in Conscientiousness are characterized as lacking self-discipline, disorganization, inefficiency, low self-discipline, and impulsivity (Costa \& McCrae, 1992, p.15-16). Low Conscientiousness has been conceptualized as a skill deficit that interferes with task completion, thus fueling feelings of incompetency and decreased perceived control over achievement tasks (Andersen \& McLean, 1997). In addition, individuals with acute depression who were low in Conscientiousness were more likely to belong to families characterized by unhealthier family functioning (Miller et al., 2000). In the current study, it was predicted that the relation between perceived criticism and depressive symptom severity would be amplified in individuals low in Conscientiousness, because these individuals may be particularly sensitive to perceived threats to self.

The third exploratory aim of the study was to examine whether patient's cognitive functioning moderates the relation between PC and depression symptom severity crosssectionally and prospectively. It was predicted that the association between PC and depressive symptom severity would be qualified by patient's cognitive functioning. 
The fourth aim of the study was to conduct an exploratory analysis examining whether living status moderates the relation between PC/EI and depression symptom severity and psychological well-being.

In addition to the above aims, a descriptive analysis exploring the family members participants reference when they completed the FEICS was conducted.

\section{Methods}

\section{Participants}

Participants were 114 adults 60 years of age and older newly $(<1$ month after intake session) receiving treatment for depressive or anxious symptomatology at a university-affiliated outpatient clinic as part of an on-going study that assessed depression and decision-making in late life. Demographics are displayed in Table 1. Of note, the sample included a greater number

of female, White, and married individuals. Prior to the research interview, chart diagnoses were made by an intake clinician (most often a clinical social worker). Table 2 displays patient diagnoses. The majority of participants held a primary diagnosis of mood disorder.

\section{Measures}

Depression symptom severity was measured with the Patient Health Questionnaire (PHQ9; Kroenke, Spitzer, \& Williams, 2001; Appendix A). The PHQ-9 is a 9-item measure of depression severity corresponding to the nine criteria upon which the diagnosis of DSM-IV depressive disorders is based. Items are scored from 0 (not at all) to 3 (nearly every day) with a minimum possible score of 0 and a maximum score of 27 . The following severity levels have been described: 0-4 minimal, 5-9 mild, 10-14 moderate, 15-19 moderately severe, and 20-27 severe (Kroenke et al., 2001). In a primary care based study of 580 participants, individuals 
diagnosed with major depressive disorder had an average PHQ-9 score of 17.1 (SD = 6.1). In addition, the investigators examined likelihood ratios of being diagnosed with major depression at different cut points of PHQ-9 scores. They found that on average, scores greater than 15 likely indicate the presence of major depression (Kroenke et al., 2001).

Psychological Well-being was assessed with a multi-dimensional measure that encompasses six dimensions thought to be associated with well-being across the life-span (Ryff, 1989; Appendix B). Each dimension includes seven items measured on a scale from 1 (strongly disagree) to 6 (strongly agree). The six dimensions include: Autonomy (“A sense of selfdetermination"), Environmental Mastery ("The capacity to manage effectively one’s life and surrounding world”), Personal Growth (“A sense of continued growth and development”), Positive Relation With Others ("The possession of quality relations with others"), Purpose in Life ("The belief that one's life is purposeful and meaningful"), and Self-Acceptance ("Positive evaluations of oneself and one's past life"). In its original conception, the items within each of the six individual dimensions were totaled to create total scores for each of the six dimensions (Ryff, 1989; Ryff \& Keyes, 1995). Psychometric evaluation since that time has revealed a second-order general well-being factor comprised of Environmental Mastery, Personal Growth, Purpose in Life, and Self-Acceptance dimensions (Abott, et al., 2006). Together, these four dimensions were found to be highly correlated, with relations between the dimensions best explained by a second-order general well-being factor. Further, this model was found to be superior in model fit compared to other models, such as a unidimensional model with all items loading on a single latent factor and a multi-dimensional model that included six single construct factors (Abott, et al., 2006). Given these findings, a total PWB score was created by summing the Environmental Mastery, Personal Growth, Purpose in Life, and Self-Acceptance. The four- 
dimension total PWB score has a minimum possible score of 28 and a maximum score of 168. Hypotheses were also tested with a total score derived from summing all six dimensions. The six-dimension total score has a minimum score of 42 and a maximum total score of 252 . For both versions, higher scores indicate greater psychological well-being. Test-retest reliability of individual factors has been examined over a six week period with coefficients ranging from .81 (Purpose in Life) to .85 (Positive Relations). Intercorrelations between dimensions have been found to range between 32 to .76 .

Family Functioning was measured with a modified version of the Family Emotional Involvement Scale (FEICS), a self-report instrument (Shields et al., 1992, 1994; Appendix C) of perceived criticism and emotional involvement. The original FEICS contains two subscales: Perceived Criticism (PC) reflects the extent to which participants report critical comments made by their family and Emotional Involvement (EI) refers to the degree to which participants endorse feelings of emotional support from their family members. Modifications were made in the wording of items and content of items by the primary investigator based on initial response by participants that the wording of items was too extreme. Each subscale includes 6-items rated on a Likert scale ranging from 1(Almost never) to 5 (Almost always) with a possible minimum score of 6 and maximum score of 30. Example items of the modified FEICS include: "My family is always trying to get me to change" (PC) and "My family encourages me to talk about my worries (EI)."

Social Support was measured with the Perceived Social Support-Family Subscale (PSSFamily; Procidano \& Heller, 1983; Appendix D), a self-report measure of the extent to which an individual perceives receiving support, information, and feedback from their family. Items include declarative statements to which individuals are given the response choices of "Yes," 
"No," or "Don't know." Affirmative responses receive 1 point, with all other responses receiving 0 points, with a minimum possible total score of 0 and maximum possible score of 20 . Higher scores are indicative of higher levels of perceived social support. An example item includes, "My family gives me the moral support I need." Initial validation of the PSS-Family by Procidano et al., (1983) found an internal consistency of .90 (Cronbach's alpha). Factor analysis demonstrated the unidimensionality of the subscale. Bivariate correlations between the PSS-Family and mental health symptoms (Langer, 1962) and a shortened form of the MMPI (FAM; Faschinghauer, 1974) were conducted to establish construct validity. PSS-family was found to correlate negatively with mental health symptoms. MMPI shortened form scales 1 (Depression), 7 (psychasthenia), and 8 (Schizophrenia) were found to be negatively correlated with PSS-family.

Personality was measured with the NEO Five-Factor Inventory (NEO-FFI; Costa \& McCrae, 1992), a 60-item, self-report inventory of personality traits grouped along five major dimensions: Neuroticism, Extraversion, Openness, Agreeableness, and Conscientiousness. Each dimension includes 12 items and responses are made on a Likert-type scale ranging from 0 (Strongly agree) to 4 (Strongly disagree). Raw subscale scores have a minimum possible score of 0 and a maximum possible score of 48 . Scores are traditionally converted to T-scores ( $M=50$, $S D=10)$. T-scores of 56 or higher are considered high, $\mathrm{T}$ scores between 55-45 average, and $\mathrm{T}$ scores below 44 are considered low (Costa \& McCrae, 1992, p.12). Neuroticism refers to an emotional vulnerability to stress that is characterized by a tendency to experience negative emotional states such as depression, anxiety, anger, and guilt. Conscientiousness refers to an individual's tendency to value actively planning, organizing and carrying out tasks. Individuals scoring high in this domain have been described as purposeful, strong-willed, and determined. Previous research has demonstrated adequate internal consistency for Neuroticism (Coefficient 
alpha $=.86)$ and Conscientiousness (alpha $=.89)$ in a sample of 1,800 adult participants recruited from a large national organization (Costa, McCrae, \& Dye, 1991). Research with older adult participants has also demonstrated adequate internal consistency (Chapman, Duberstein, Sörensen, \& Lyness, 2006). The NEO-FFI has demonstrated convergent validity with adjective self-reports with correlations ranging from .56 to .62 (McCrae \& Costa, 1985b).

Cognitive Status was measured using the Montreal Cognitive Assessment (MoCA; Appendix E) a brief, 30-item screening tool for mild cognitive impairment (Nasreddine et al., 2005). A cut-off score of $26 / 30$ has been shown to accurately detect $90 \%$ of subjects positive for mild cognitive impairment. The degree to which the MoCA accurately excludes (specificity) normally functioning participants is $87 \%$.

\section{Procedures}

The current investigation is part of a larger, on-going study that assessed depression and decision-making in late-life. From April 2008 to April 2010, clerical staff members distributed letters of invitation to new patients immediately preceding their initial clinic appointment. Interested participants who were 60 years of age or older and English speaking were then contacted by a member of the research team. Of the 543 patients invited to participate, 285 declined outright and 258 agreed to be contacted by a research assistant. Of the 258 who were contacted, 114 provided informed consent to participate, 72 declined, and 72 were deemed ineligible due to the presence of dementia, schizoaffective disorder, or schizophrenia (see Figure $1)$.

Study entry interviews took place at the clinic or at the participants' residence, according to their preference. Demographics, as well as study entry levels of depression, perceived family 
functioning, personality, and cognitive status were assessed within one month following initial presentation to the clinic. Follow-up phone interviews took place once a month for five consecutive months after the initial interview. In-person interviews were conducted six months after the initial interview. The current study uses data from the initial intake interview (Time 1) and from the final, in-person interview, which will be referred to as Time 2 . Of the 114 participants who completed Time 1 interviews, 74 completed follow-up measurement of PHQ-9, an in-person questionnaire. Of these 74 participants, a total of 42 participants mailed back the PWB measure.

\section{Results}

All analyses were conducted using PAWS Statistic 18.0, SAS (v. 9.2) and SPSS Amos Version 19.

Missing Data Analyses. Prior to conducting analyses, study variables were examined for missing data. Percentage of missing data by variable and time point is listed in Table 3 .

In order to examine whether individuals with missing data differed from individuals without missing data, independent sample t-tests for age and education (continuous variables) and Chi-Square Tests of Independence were conducted for gender and race (categorical variables). Results revealed that the four participants with missing MOCA scores were significantly older $(M=70.2, S D=8.7)$ compared to the 109 participants with MOCA scores $(M$ $=62.0, S D=1.8), t(9.9)=-6.61, p<.001$. Examination of equality of variances revealed this assumption was violated as indicated by the Folded F test. Therefore, the Satterthwaite method for unequal variances was used. Results also found that the 21 participants with missing data for Conscientiousness had significantly less education $(M=12.3, S D=2.4)$ compared to the 88 participants with complete data $(M=14.1, S D=2.9), t(107)=-2.55, p<.05$. Participants with 
missing compared to non-missing data were not significantly different on any other demographic variables. This pattern of missing data satisfies the criterion for data missing at random (MAR), because missingness was associated with other study variables in the dataset (Schafer \& Graham, 2002; Tabachnick \& Fidell, 2007, pp. 62-63).

Additional independent sample t-tests were conducted to examine whether missingness on study variables was related to the dependent variables, including PHQ-9 and PWB at Time 1 and Time 2, which would also satisfy the criteria for MAR (Schafer \& Graham, 2002). Results indicated that the eight participants with missing data on the Neuroticism domain score were significantly higher on PHQ-9 scores at Time $2(M=12.0, S D=6.2)$ compared to the 65 participants without missing data $(M=7.0, S D=5.0), t(71)=2.5, p<.05$. In addition, the four participants with missing data for Neuroticism were significantly lower on PWB at Time $1(M=$ $61.8, S D=9.0)$ compared to the 65 participants without missing data $(M=84.1, S D=13.6)$, $t(67)=-3.24, p<.05$.

Results also indicated that the ten participants with missing data for Conscientiousness domain score were significantly higher on PHQ-9 scores at Time $2(M=12.2, S D=6.5)$ compared to the 63 participants without missing data $(M=6.8, S D=4.8), t(71)=3.14, p<.01$. Further, the eight participants with missing data for Conscientiousness were significantly lower on PWB at Time $1(M=73.1, S D=18.6)$ compared to the 61 participants without missing data $(M=84.1, S D=13.3), t(67)=-2.09, p<.05)$.

Findings also revealed that the 44 participants with missing data for PWB at Time 1 were significantly higher on the PHQ-9 at Time $1(M=11.4, S D=6.6)$ compared to the 69 participants without missing data $(M=7.8, S D=5.6), t(111)=-3.11, p<.01)$. In addition, the 23 participants with missing data for PWB at Time 1 also were significantly higher on PHQ-9 at 
Time $2(M=9.6, S D=5.9)$ compared to the 50 participants without missing data $(M=6.6, S D=$ 4.9), $t(71)=-2.30, p<.05$.

Finally, results found that the 75 participants with missing data on PWB at Time 2 were significantly higher on PHQ-9 at Time $1(M=6.4, S D=.74)$ compared to the 38 participants without missing data $(M=7.6, S D=5.5), t(111)=-2.08, p<.05)$. In addition, the 38 participants with missing data for PWB at Time 2 were significantly higher on PHQ-9 at Time $2(M=8.8$, $S D=5.7)$ compared to the 35 participants without missing data $(M=6.2, S D=4.7), t(71)=--$ $2.16, p<.05)$.

Handling Missing Data. Multiple imputation was used in order to estimate missing total scores. Multiple imputation is a preferred method for handling missing data because all available data are used to create plausible values across $m$ imputed datasets with complete data filled in (Rubin, 1996). This approach reduces the likelihood of biased parameter estimates compared to other methods, such as list-wise deletion, because missing data are predicted from participants' observed values (Schafer \& Graham, 2002). ${ }^{1}$ In the present study, five imputed data sets were created, which has been found to be a sufficient number to estimate missing values (Rubin, 1987). Following this step, inferential statistics were found for the original dataset and each individual imputed dataset. Lastly, data were combined into pooled statistics. Multiple imputation was conducted using SAS PROC MI.

Attrition. Independent sample t-tests and Chi-Square Tests for Independence were conducted to examine whether participants who dropped out of the study were significantly different from participants who remained in the study. Over the course the study, a total of 41 participants (36.0\% of the sample) dropped out. Results revealed that participants who dropped out of the study had significantly lower MOCA scores $(M=21.2, S D=19.5)$ compared to participants who 
remained in the study $(M=23.5, S D=22.6), t(62.0)=2.54, p<.05$. Examination of equality of variances revealed this assumption was violated as indicated by the Folded F test. Therefore, the Satterthwaite method for unequal variances was used. Participants did not differ significantly on any other study variables.

Assumptions. Prior to conducting analyses, assumptions of univariate and multivariate statistics were tested. Outliers were analyzed by converting total scores into Z-scores. The minimum and maximum of the Z-scores were examined. Values > 3.29 were considered outliers (Tabachnick \& Fidell, 2007, pp.73). One outlier was revealed on Conscientiousness with a Z-score of 3.6 (raw score $=44)$. The case was visually inspected to explore whether it was part of the intended sample. The case was selected to remain in the sample, given that it was not too extreme. Normality of the data was examined by calculating the skew and kurtosis for each variable. Values were < 3.29 (Tabacknick \& Fidell, 2007, pp. 79), thus this assumption was met. Unimodality of the data was also tested by examining frequency distributions for all study variables. Based on visual inspection, the frequency distribution of study variables appeared unimodal. Next, linearity of the data was examined by observing scatterplots between the dependent variables (PHQ-9 and PWB at Time 1 and Time 2) and main independent variables (PC and EI). Visual inspection of the scatterplots revealed that each combination of IVs and DVs appear to share a linear relation, thus satisfying the assumption of linearity.

Following examination of univariate assumptions, assumptions underlying multiple regression analyses were examined. First, we examined multivariate outliers including, Mahalanobis distance, Leverage, Discrepancy, and Influence. In order to find outliers across all independent variables at once, a multiple regression analysis was conducted in SPSS. The dependent variable was case number and the independent variables of interest were entered, 
including PC, EI, Neuroticism, Conscientiousness, and MOCA scores. For the present sample, Mahalanobis difference value exceeding 20.515 was considered extreme $(\mathrm{df}=5, \alpha=.001$; Tabachnick \& Fidell, 2007, pp.949). Mahalanobis distance was 4.9, below the critical threshold. Leverage, a measure of how far a case is from the rest of the data, was .065 , below the critical threshold of $.13 .^{2}$ Next, Discrepancy, or the extent to which a case is in line with others, was examined by visual inspection of a scatter plot of the studentized residuals on the $\mathrm{Y}$-axis and case-number on the X-axis. Visual inspection revealed no problems with discrepancy. Influence was examined (Cook's distance), which is the amount of change in the regression equation when a case is deleted. It is calculated by a combination of Leverage and Discrepancy. Cook's distance was .014 , which is below the critical threshold of .06 (Cook, 1977). ${ }^{3}$

Multivariate normality was examined by plotting standardized predicted values of the dependent variables on the $\mathrm{X}$-axis and standardized residuals (error) on the $\mathrm{Y}$-axis. In order to meet multivariate assumption of normality, upon visual inspection errors of prediction should be normally distributed around predicted values of dependent variables (Tabachnick \& Fidell, 2007, pp.127). This appeared to be the case.

Finally, heteroscedasticity was also examined in the same plot. Heteroscedasticity is met when "standard deviations of errors of prediction are approximately equal (Tabachnick \& Fidell, 2007, pp.127).” Indication of violation of this assumption is evidence through visual examination of the residuals around the predicted dependent variable. Ideally, residuals should be an equal width from all values of the predicted dependent variables. Visual inspection of scatterplots with the four proposed dependent variables revealed some problems with heteroscedasticity; however, regression is relatively robust to minor violations of this assumption (Tabachnick \& Fidell, 2007, pp.127). 
Descriptives. First, a confirmatory factor analysis (CFA) was conducted to examine whether the modified version of the FEICS used in the present study fit the original two-factor structure of the measure. Based on the two-factor model, 6-items were predicted to load on the Perceived Criticism factor and 6-items were predicted to load on the Emotional Involvement factor. The data fit the hypothesized model poorly, $\chi^{2}(53, N=114)=209.47, p<.001$. The relative chi square, which is the ratio of the chi square value over degrees of freedom, was 3.95. Values less than 3.0 are considered indicative of a well-fitting model. The Comparative Fit Index (CFI) also indicated poor model fit to the original two-factor model, $\mathrm{CFI}=.48$ (values $>.95$ indicate good fit). Finally, the Root Mean Square Error of Approximation (RMSEA) was .16. Although sensitive to sample size, .16 is above the recommended criterion of RMSEA values less than .06 suggestive of good model fit (Tabachnick \& Fidell, 2007, pp.715-719). Given these findings, the modified FEICS appeared to fit the original two-factor structure found in the original FEICS poorly. However, given sample size limitations, these results should be interpreted with caution because Structural Equation Modeling underlying CFA are suited best for larger sample sizes. In the current study, with 53 degrees of freedom, in order to reach .80 power, the suggested sample size is > 200 (MacCallum, Browne, \& Sugawara, 1996). Given this consideration, internal consistency of Perceived Criticism and Emotional Involvement subscales were examined.

The Perceived Criticism subscale was examined first. Internal consistency of the subscale was adequate, $\alpha=.62$. Item-total correlations ranged from .42 to .62, except for one item ("My family approves of the way I live my life") which had a lower item-total correlation of .18. However, deletion of this item would only increase the internal consistency to .70; therefore, this item was retained. Second, the Emotional Involvement subscale was examined. Internal 
consistency of the subscale was also adequate, $\alpha=.84$. Item-total correlations ranged from .51 to .77. Overall, the reliability of the subscales suggested that they were adequate for subsequent analyses; caution is warranted when interpreting the results as they do not fit the original FEICS two-factor model.

Descriptive analyses of all study variables, including means, standard deviations, range, and Cronbach's alphas are included in Table 4. Alphas demonstrated acceptable internal reliability for all study measures. Of note, PHQ-9 scores were in the mild depression severity range at Time 1 . By Time 2, there was a significant 1.5 point decrease in the overall mean, $t(72)$ $=2.52, p<.05)$. Similarly, PWB scores improved by 2.5 points overall; however, this did not reach statistical significance, $t(32)=-1.96, p=.06$.

Next, descriptive statistics were examined for five items of the FEICS in which participants were asked to rate on a scale ranging from 1 (not at all) to 5 (very much) "How much were you thinking of your relationship with each of these people.”. Participants endorsed an mean of $3.6(\mathrm{SD}=1.5)$ in regards to their children, $\mathrm{M}=2.8(\mathrm{SD}=1.5)$ for their siblings, $\mathrm{M}=$ $2.7(\mathrm{SD}=$ for their spouse or partner, $\mathrm{M}=2.4(\mathrm{SD}=1.5)$ for their family in which they grew up, and $2.0(\mathrm{SD}=1.4)$ for their relationship with their parents now. Over half of participants $(53.4 \%)$ endorsed 4 or 5 in relation to thinking of their relationship with their children. $39.3 \%$ of participants endorsed a 4 or 5 in relation to thinking of their relationship with their spouse or partner. Nearly $38 \%$ of participants endorsed a 4 or 5 in relation to thinking of their relationship with their siblings. $27.4 \%$ of participants endorsed a 4 or 5 in relation to thinking of their relationship with their family in childhood. A minority of the sample (20.9\%) endorsed a 4 or 5 in relation to thinking of their relationship with their parents now. 
Relations between study variables were examined through bivariate correlations. Pooled correlation coefficients are presented in Table 5. PC was significantly and positively associated with PHQ-9 at Time 1, but not significantly associated with PHQ-9 at Time 2. Further, PC was significantly and negatively associated with PWB at Time 1, but not significantly associated with PWB at Time 2. EI was not significantly associated with PHQ-9 at either Time 1 or Time 2, but EI was significantly and positively associated with PWB at Time 1. EI was not significantly related to PWB at Time 2.

Next, the study aimed to examine the cross-sectional and prospective relations between PC and depressive symptom severity (Aim 1). A linear regression analysis was examined with age and PC entered predicting PHQ-9 scores at Time 1. It was hypothesized that PC would be positively associated with PHQ-9 scores, after controlling for demographics variables (age was the only demographic variable related to PHQ-9). PC was significantly associated with PHQ-9 scores at Time 1 , after controlling for age, $(B=.34$, SE $=.14, p<05$. $)$. PC accounted for significant variance in PHQ-9 scores, $\left(\mathrm{R}^{2}=.06\right)$.

A second linear regression analysis was created to examine the prospective relation between PC and PHQ-9 at Time 2, after controlling for age and PHQ-9 scores at Time 1. Again, it was predicted that PC would be positively associated with PHQ-9, after accounting for depression symptom severity at Time 1. After controlling for age and PHQ-9 scores at Time 1, PC was nonsignificant, $(B=.05, \mathrm{SE}=.16, p=.75)$. Tables $6 \& 7$ present cross-sectional and prospective analysis for the listwise, imputed, and pooled statistics.

The study also aimed to examine the cross-sectional and prospective relations between PC and PWB (Aim 1). It was hypothesized that PC would be negatively associated with PWB scores. No demographics were controlled for because examination of bivariate correlations 
revealed that they were not significantly associated with PWB. This hypothesis was partially supported. At Time 1, participants with higher PC scores were lower in PWB, $(B=-1.23, \mathrm{SE}$ $=.40, p<.01)$, and PC scores accounted for significant variances in PWB scores, $\left(\mathrm{R}^{2}=.14\right)$. However, PC was not significantly associated with PWB scores at Time 2, after controlling for PWB scores at Time $1,(B=-.39, \mathrm{SE}=.44, p=.42)$. Tables $8 \& 9$ present cross-sectional and prospective analysis for the listwise, imputed, and pooled statistics.

Third, Neuroticism was examined as a potential moderator of the relation between PC and PHQ-9 both cross-sectionally and prospectively (Aim 2). It was hypothesized that the relation between PC and PHQ-9 would be amplified in participants high in Neuroticism. PHQ-9 at Time 1 was regressed onto PC x Neuroticism. Neuroticism did not moderate the relation between PC and PHQ-9 at Time $1,(B=.0004, \mathrm{SE}=.02, p=.797)$, after controlling for age, PC and Neuroticism scores. Main effects were found for Neuroticism, $(B=.29, \mathrm{SE}=.07, p<.01)$. In addition, a main effect was also found for age, $(B=-.14, \mathrm{SE}=.06, p=.01)$.

Similar findings were found when PHQ-9 at Time 2 scores were regressed onto PC $\mathrm{x}$ Neuroticism, after controlling for age, PC, Neuroticism, and PHQ-9 Time 1 scores. The interaction was nonsignificant, $(B=.006, \mathrm{SE}=.02, p=.74)$. Main effects were found for PHQ-9 at Time $1,(B=.43, \mathrm{SE}=.09, p<.001)$.

Conscientiousness was also examined as a potential moderator of the relation between PC and PHQ-9 (Aim 2). Contrary to the prediction that individuals scoring low in Conscientiousness would demonstrate an amplified relation between PC and PHQ-9, the interaction was nonsignificant, $(B=.01, \mathrm{SE}=.02, p=.52)$. A main effect was found for Conscientiousness predicting depression symptom severity at Time $1,(B=-.24, \mathrm{SE}=.08, p<.01)$ Similarly, the interaction between PC and Conscientiousness was also nonsignificant in the prospective 
analysis, $(B=-.01, \mathrm{SE}=.02, p=.42)$. A main effect was found for Conscientiousness predicting depression symptom severity at Time $2,(B=-.22, \mathrm{SE}=.09, p<.05)$.

Next, the cross-sectional and prospective relation between EI and PHQ-9 was examined by regressing PHQ-9 scores onto EI, controlling for age, PC, and PSS, as well as PHQ-9 at Time 1 (prospective only; Aim 1). It was predicted that EI would be positively associated with PHQ-9 scores, after controlling for PC and PSS. At Time 1, EI was not significantly associated with PHQ-9 scores, $(B=.11, \mathrm{SE}=.15, p=.60)$. It should be noted however, that as hypothesized, when PC and PSS were controlled for, the sign of the regression coefficient, although nonsignificant flipped in the opposite direction from the bivariate correlations between EI and PHQ-9 scores. That is, individuals with higher EI scores (indicative of extreme closeness) trend towards having increased depression scores. EI was not significantly associated with PHQ-9 scores at Time 2, after controlling for PC, PSS, and PHQ-9 at Time 1, $(B=-.12, \mathrm{SE}=.26, p=$ .48). An alternative regression model was run, without controlling for PSS, in order to more clearly examine the relation between EI and PHQ-9, controlling for PC. In these models, EI was still not significantly associated with PHQ-9 (results not reported). Tables $10 \& 11$ present crosssectional and prospective analysis for the listwise, imputed, and pooled statistics.

The relation between EI and PWB (Aim 1) was examined. It was predicted that EI would be negatively associated with PWB, after PC and PSS were partialled out. In a linear regression analysis, PWB at Time 1 (cross-sectional) was regressed onto PC, PSS, and EI. EI was not significantly associated with $\mathrm{PWB},(B=.30, \mathrm{SE}=.51, p=.56)$. An identical model was created to examine the prospective association between EI and PWB at Time 2, but also controlling for PWB at Time 1. Similarly, EI was not significantly associated with PWB scores at Time 2, after 
controlling for PC, PSS, and PWB scores at Time $1,(B=-.50 \mathrm{SE}=.61, \mathrm{p}=.45)$. Tables $12 \& 13$ present cross-sectional and prospective analysis for the original, imputed, and pooled statistics.

An exploratory multiple regression analysis was conducted to examine whether MOCA scores moderated the relation between PC and PHQ-9 scores cross-sectionally and prospectively (Aim 4). It was predicted that MOCA scores would amplify the relation between PC and PHQ-9. This hypothesis was not supported. MOCA scores did not qualify the relation between PC and PHQ-9 at Time $1,(B=-.07, \mathrm{SE}=.04, p=.08)$ or at Time $2,(B=.01, \mathrm{SE}=.04, p=.78)$. Main effects were found for age at Time 1 (previously reported). Main effects at Time 2 were found for MOCA scores, $(B=-.36, \mathrm{SE}=.14, p<.05)$ and PHQ-9 at Time $1,(B=.51, \mathrm{SE}=.09, p<$ $.001)$.

Lastly, additional exploratory analyses were conducted examining whether living status (alone vs. not alone) qualified the relation between PC and EI and outcomes variables (PHQ-9 and PWB) at Time 1 and Time 2 (Aim 5). In the first regression equation, PHQ-9 at Time 1 was regressed onto PC x living status, controlling for age, living status, and PC scores. This interaction was not significantly associated with PHQ-9 at Time $1,(B=.40, \mathrm{SE}=.26, p=.12)$. In the second equation, PHQ-9 at Time 2 was regressed onto PC x living status, controlling for age, living status, PC scores and PHQ-9 scores at Time 1. This was also not significantly associated with PHQ-9 scores at Time $2,(B=-.13, \mathrm{SE}=.26, p=.62)$. Identical equations were created for PWB scores at Time 1 and Time 2. The interaction term between PC $\mathrm{x}$ living status predicting PWB scores at Time $1,(B=-.27, \mathrm{SE}=1.08, p=.81)$ and Time 2 was not significant, $(B=-.02, \mathrm{SE}=.40, p=.95)$.

Identical analyses were conducted with EI x living status interaction predicting PHQ-9 and PWB at Time 1 and Time 2. Results revealed that the interaction was not significantly 
associated with PHQ-9 scores at Time $1,(B=.21, \mathrm{SE}=.24, p=.40)$ and Time $2,(B=-.09, \mathrm{SE}=$ $.24, p=.71)$. Findings also that EI x living status was not significantly associated with PWB scores at Time $1,(B=.36, \mathrm{SE}=.70, p=.61)$ and $\mathrm{PWB}$ at Time $2,(B=-.17, \mathrm{SE}=.30, p=.58)$.

\section{Discussion}

The current study examined the cross-sectional and prospective relations of perceived criticism and emotional involvement with depressive symptom severity and psychological well being in older adults newly seeking treatment for depression and anxiety. In addition, potential moderators of these relations were examined, including personality variables (Neuroticism and Conscientiousness), cognitive functioning, and living status.

Results demonstrated that individuals with increased perceived criticism also had greater depressive symptom severity, at least measured at one point in time. Perceived criticism failed to predict change in depression symptom severity in the prospective analyses. Similarly, perceived criticism was associated with lower psychological well-being in the cross-sectional analyses; however, perceived criticism failed to predict change in psychological well-being in prospective analyses. No significant interactions were found with perceived criticism, suggesting at least in the current study, personality variables, cognitive functioning, and living status did not qualify the relation between perceived criticism and depression symptom severity or change in depression symptom severity over time. Contrary to predictions, EI was not significantly associated with depression symptom severity and psychological well-being cross-sectionally and prospectively, after controlling for perceived criticism and perceived social support from family.

Results of the present study confirm and contrast with previous findings examining perceived criticism and emotional involvement in older adults. Similar to previous findings, increased perceived criticism was associated with greater depression symptom severity at Time 
1. This cross-sectional finding parallels results in a sample of older adult primary care patients, in which increased perceived criticism was associated with greater depression symptom severity and depression diagnosis. The finding is also in agreement with findings in adult primary care patients, in which perceived criticism was positively associated with depression (Shields et al., 1992, 1994).

However, the prospective relation between perceived criticism and depression symptom severity was not significant after controlling for baseline depression symptom severity and age. Given that perceived social support has been found to be independently associated with depression symptoms in treatment-seeking older adults longitudinally, it is possible that positive social exchanges are more important predictors of depression symptom change over time (George et al., 1989; Steffen et al. 2008). In support of this idea, research examining the relation between positive and negative social exchanges and depressive symptoms in communitydwelling older adults has found that positive social exchanges exerted a stronger effect on depressive symptoms compared to negative social exchanges (Okun \& Keith, 1998). However, contrary findings have been observed among community-dwelling older adults as well, with increases in negative social exchanges, but not positive social exchanges, associated with increases in depressive symptoms prospectively (Finch \& Zatura, 1992; Rook, 2001). Given the mixed findings regarding how positive and negative aspects of social relations influences depressive symptoms, additional research is needed to elucidate these effects.

Further, no moderation effects were found for personality variables, cognitive functioning, or living status. This was the first study to test the influence of moderator variables using the FEICS. Previous studies have found main effects for personality variables using selfreport and observer-rated measures of overall family functioning. Unlike previous studies (Miller 
et al., 2000), the current study examined two aspects of family functioning, perceived criticism and emotional involvement. It is possible that personality variables, when tested with additional measures of family functioning, may demonstrate significant moderator effects. Similarly, additional research is needed to examine whether cognitive functioning and living status influence the relation between measures of family functioning and/or positive/negative social exchanges and depressive symptoms.

The current study also tested the cross-sectional and prospective relation between perceived criticism and psychological well-being. Results of the current study revealed a significant cross-sectional relation, but nonsignificant prospective relation between perceived criticism and psychological well-being. At Time 1, older adults with increased perceived criticism had lower psychological well-being. This finding suggests that when measured at one point in time, perceived criticism dampens overall emotional health, including positive facets of emotional health. This is in line with previous research that has shown negative social exchanges to dampen well-being (measured by a subscale on the CES-D; Rook, 2001).

The relation between emotional involvement and depressive symptom severity was also examined, after controlling for age, perceived criticism, and perceived social support. The results at both time points were non-significant. Further, the cross-sectional and prospective relation between emotional involvement and psychological well-being revealed non-significant findings, suggesting that after controlling for perceived criticism and perceived social support, emotional involvement is no longer related to psychological well-being. However, in line with previous findings, once PC and social support were partialled out, emotional involvement, although not significant, became positively associated with depression symptom severity. This finding in in 
line with results by Shields et al. $(1992,1994)$ who found that once PC and social support were controlled for, emotional involvement was positively associated with depression.

From a clinical perspective, recognition that perceived criticism is associated with depressive symptom severity and reduced psychological well-being is meaningful. Social network size decreases with age (van Tilburg, 1998); however, enhancing close relations becomes a priority (Cartensen, 1995). The presence of negative exchanges, such as interactions high in criticism, may hurt older adults' ability to derive positive support from social relations with others in their social network. Evidence of such an occurrence has been found in older adult women, in which a troubled relationship with adult children was associated with difficulty engaging positively with fellow residents of an apartment complex (Hochschild, 1975). Therapies aimed at problem-solving around interpersonal tensions, such as interpersonal psychotherapy (Reynolds et al., 1999a, 1999b), may be particularly useful for older adults experiencing recurring interpersonal conflict. Further, attention to the relation between interpersonal-conflict and depressed mood in therapy may be beneficial for older adults when role transitions and loss of independence creates physical dependence on others. Lastly, such therapies may benefit from focusing on familial relations compared to friendships, since it is within the family context that the most care is provided and the most frequent negative social exchanges are reported (Swindle, Heller, Alexander, Allen \& Wyman, 2001).

\section{Limitations and Future Directions}

Several limitations of the present study warrant attention. First, perceived criticism and emotional involvement were measured with self-report instruments. Although this provided information regarding the patients' perception of negative aspects of social relations, additional measures, including observer-based and perceptions from identified members of the social 
network are needed. Discrepancy between patient and informant perceptions of negative social exchanges may be useful to capture, as they may represent impasses towards conflict resolution. Such interpersonal dilemmas may be particularly influential on mood and well-being, and the target of therapeutic intervention.

Second, the FEICS lacked specification of the relationships in which patients were responding. For instance, the FEICS did not have participants rate items based on a specified individual. Identification of the relationships high in perceived criticism and lacking emotional involvement would inform both research aimed at identifying relationships most important for predicting mental health outcomes and within the context of clinical work, in which identification of problematic interpersonal relationships is the target of intervention. Future research that includes measures in which participants answer questions regarding specific relationships (i.e. spouse, adult child, etc.) is needed.

Third, life stressors have been shown to interact with negative social exchanges in relation to depression (Rook, 2001) and future research would benefit from measuring life stressors in relation to the influence of social support variables on depression and psychological well-being. Common life stressors in older adulthood include functional limitations and cognitive decline. Previous research has shown that both functional and cognitive impairment are independent predictors of depression in older adults (Vinkers, Gussekloo, Stek, Westendorp, \& van der Mast, 2004; Zeiss, Lewinsohn Rohde, \& Steely, 1996); however, it is unknown whether negative social exchanges may interact with these changes to further increase depression symptoms and dampen psychological well-being. In addition, the interaction between life stressors (e.g. functional limitations) and negative social exchanges may be most detrimental in 
those who report difficulty coping with decreases in functioning. Future research is required to examine the relations between life stressors, negative social exchanges, and depression.

Finally, the current study extended previous research examining the relation between the FEICS and depression symptom severity and psychological well-being prospectively.

Nonetheless, future research that examines the day-to-day influence of negative exchanges on mood would elucidate how negative interactions actually perpetuate depressed mood via daily levels of positive and negative affect. Studies using experience sampling methods, in which the frequency of negative social exchanges and mood are captured on a day-to-day basis, would provide information regarding how negative exchanges relate to subsequent mood levels. Further, within such a model, cross-level interactions with patient factors, such as personality and cognitive functioning could be tested.

\section{Conclusions}

The current study demonstrated that perceived criticism was associated with greater depression symptom severity, as well as lower psychological well-being among treatmentseeking older adults measured cross-sectionally. Perceived criticism did not predict change in depression symptom severity and psychological well-being after six months in treatment. In addition, personality variables, cognitive functioning, and living status did not influence the relation between perceived criticism and depression symptom severity. Finally, after controlling for perceived criticism and perceived social support, emotional involvement was not related to depression symptoms severity or psychological well-being at the beginning of treatment or after six months. 


\section{Notes}

1. Multiple imputation was also run using a method proposed by von Hippel (2007) that extracts cases with missing dependent variables. Results did not differ from multiple imputation without deletion of dependent variables.

2. Based on Tabachnick \& Fidell, 2007, pp. 74 reference to "Lunneborg (1994) who suggested that outliers be defined as cases with with $h_{i i} \geq 2(k / N)$.

3. Based on the equation $4 /(n-k-1)$. 


\section{References}

Abbott, R.A., Ploubidis, G.B., Huppert, F.A., Kuh, D., Wadsworth, M.E.J., \& Croudace, T.J. (2006). Psychometric evaluation and predictive validity of Ryff's psychological wellbeing items in a UK birth cohort sample of women. Health and Quality of Life Outcomes, 4, 1-16. doi: 10.1186/1477-7525-4-76

Alexopoulos, G. S., Buckwalter, K., Olin, J., Martinez, R., Wainscott, C., \& Krishnan, K. R. R. (2002). Comorbidity of late life depression: An opportunity for research on mechanisms and treatment. Biological Psychiatry, 52, 543-558. doi: 10.1016/S0006-3223(02)01468-3

Andersen, K.W., \& McLean, P.D. (1997). Conscientiousness in depression: tendencies, predictive utility, and longitudinal stability. Cognitive Therapy and Research, 21, 223238.

Beekman, A. T., Geerlings, S. W., Deeg, D. J., Smit, J. H., Schoevers, R. S., de Beurs, E., . . van Tilburg, W. (2002). The natural history of late-life depression: A 6-year prospective study in the community. Archives of General Psychiatry, 59, 605-611.

Brown, G. W., Birley, J. L., \& Wing, J. K. (1972). Influence of family life on the course of schizophrenic disorders: A replication. British Journal of Psychiatry, 121, 241-258. doi:10.1192/bjp.121.3.241

Bruce, M. L., Seeman, T. E., Merrill, S. S., \& Blazer, D. G. (1994). The impact of depressive symptomatology on physical disability: MacArthur studies of successful aging. American Journal of Public Health, 84, 1796-1799.

Callahan, C. M., Wolinsky, F. D., Stump, T. E., Nienaber, N. A., Hui, S. L., \& Tierney, W. M. (1998). Mortality, symptoms, and functional impairment in late-life depression. Journal of General Internal Medicine, 13, 746-752. 
Cartensen, L.L. (1995). Evidence for a life-span theory of socioemotional selectivity. Current Directions in Psychological Science, 4, 151-156.

Chapman, B.P., Duberstein, P.R., Sorensen, S., \& Lyness, J.M. (2006). Personality and perceived health in older adults: the five factor model in primary care. Journal of Gerontology B Psychological and Social Sciences, 61, P362-P365.

Conwell, Y., Duberstein, P. R., Cox, C., Herrmann, J. H., Forbes, N. T., \& Caine, E. D. (1996). Relationships of age and axis I diagnoses in victims of completed suicide: A psychological autopsy study. The American Journal of Psychiatry, 153, 1001-1008.

Cook, D.R. (1977). Detection of influential observation in linear regression. Technometrics, 19, 15-18.

Costa, P.T., Jr.,\& McCrae, R.R. (1992). Revised NEO Personality Inventory (NEO-PI-R) and NEO Five-Factor Inventory (NEO-FFI) manual. Odessa, FL: Psychological Assessment Resources.

Costa, P.T., Jr., \& McCrae, R.R. (1985b). The NEO Personality Inventory Manual. Odessa, FL: Psychological Assessment Resources.

Costa, P.T., Jr., McCrae, R.R., \& Dye, D.A. (1991). Facet scales for Agreeableness and Conscientiousness: A revision of the NEO Personality Inventory. Personality and Individual Differences, 12, 887-898.

Coyne, J. C., \& Downey, G. (1991). Social factors and psychopathology: Stress, social support, and coping processes. Annual Review of Psychology, 42, 401-425. doi:10.1146/annurev.ps.42.020191.002153 
Coyne, J.C., Kessler, R.C., Tal, M., Turnbull, J., Wortman, C.B., \& Greden, J.F. (1987). Living with a depressed person. Journal of Consulting and Clinical Psychology, 55, 347-352. doi: 10.1037/0022-006X.55.3.347

Crystal, S., Sambamoorthi, U., Walkup, J. T., \& Akincigil, A. (2003). Diagnosis and treatment of depression in the elderly medicare population: Predictors, disparities, and trends. Journal of the American Geriatrics Society, 51, 1718-1728.

Daniels, D., Dunn, J., Furstenberg, F. F.,Jr, \& Plomin, R. (1985). Environmental differences within the family and adjustment differences within pairs of adolescent siblings. Child Development, 56, 764-774.

Dew, M. A., Reynolds, C. F.,3rd, Houck, P. R., Hall, M., Buysse, D. J., Frank, E., \& Kupfer, D. J. (1997). Temporal profiles of the course of depression during treatment. predictors of pathways toward recovery in the elderly. Archives of General Psychiatry, 54, 10161024.

Faschinghauer, T.R.A. A 166-item written short form of the group MMPI: The FAM. Journal of Consulting and Clinical Psychology, 42, 645-656.

Finch, J. F., Okun, M. A., Barrera, M., \& Zautra, A. J. (1989). Positive and negative social ties among older adults: Measurement models and the prediction of psychological distress and well-being. American Journal of Community Psychology, 17, 585-605. doi:10.1007/BF00922637

Finch, J.F., \& Zautra, A.J. (1992). Testing latent models of social ties and depression among the elderly: a comparision of distribution-free and maximum likelihood estimates with nonnormal data. Psychology \& Aging, 7, 107-118. 
Fiore, J., Becker, J., \& Coppel, D. B. (1983). Social network interactions: A buffer or a stress. American Journal of Community Psychology, 11, 423-439.

Franks, P., Campell, T.L., \& Shields, C.G. (1992). Social relationships and health: the relative roles of family functioning and social support. Social Science \& Medicine, 34,79-88.

Franks, P., Shields, C., Campbell, T., McDaniel, S., Harp, J.,\& Botelho, R. J. (1992). Association of social relationships with depressive symptoms: Testing an alternative to social support. Journal of Family Psychology, 6, 49-59. doi:10.1037/0893-3200.6.1.49

George, L. K., Blazer, D. G., Hughes, D. C., \& Fowler, N. (1989). Social support and the outcome of major depression. The British Journal of Psychiatry : The Journal of Mental Science, $154,478-485$.

Hinrichsen, G. A., Hernandez, N. A., \& Pollack, S. (1992). Difficulties and rewards in family care of the depressed older adult. The Gerontologist, 32, 486-492.

Hooley, J.M., Orley, J., \& Teasdale, J.D. Levels of expressed emotion and relapse in depressed patients. The British Journal of Psychiatry, 148, 642-647.

Hochschild, A. (1975). The unexpected community. Englewood Cliffs, NJ: Prentice Hall.

Kiecolt-Glaser, J.K., McGuire, L., Robles, T. F., \& Glaser, R. (2002). Psychoneuroimmunology:

Psychological influences on immune function and health. Journal of Consulting and Clinical Psychology, 70, 537-547.

Krause, N. (1986). Social support, stress, and well-being among older adults. Journal of Gerontology, 41, 512-519.

Krishnan, K. R., Delong, M., Kraemer, H., Carney, R., Spiegel, D., Gordon, C., ... Wainscott, C. (2002). Comorbidity of depression with other medical diseases in the elderly. Biological Psychiatry, 52, 559-588. 
Kroenke, K., Spitzer, R. L., \& Williams, J. B. (2001). The PHQ-9: Validity of a brief depression severity measure. Journal of General Internal Medicine, 16, 606-613.

Langer, T.S. (1962). A twenty-two item screening score of psychiatric symptoms indicating impairment. Journal of Health and Human Behavior, 3, 269-275.

Leff, J \& Vaughn, C. (1981). The role of maintenance therapy and relatives' expressed emotion in relapse of schizophrenia: a two-year follow-up. The British Journal of Psychiatry, $139,102-104$.

Luber, M. P., Hollenberg, J. P., Williams-Russo, P., DiDomenico, T. N., Meyers, B. S., Alexopoulos, G. S., \& Charlson, M. E. (2000). Diagnosis, treatment, comorbidity, and resource utilization of depressed patients in a general medical practice. International Journal of Psychiatry in Medicine, 30, 1-13.

Luber, M. P., Meyers, B. S., Williams-Russo, P. G., Hollenberg, J. P., DiDomenico, T. N., Charlson, M. E., \& Alexopoulos, G. S. (2001). Depression and service utilization in elderly primary care patients. The American Journal of Geriatric Psychiatry: Official Journal of the American Association for Geriatric Psychiatry, 9, 169-176.

MacCallum, R.C., Browne, M.W., \& Sugawara, H.M. (1996). Power analysis and determination for sample size for covariance structure modeling. Psychological Methods, 1, 130-149.

Marcus, S. C., \& Olfson, M. (2010). National trends in the treatment for depression from 1998 to 2007. Archives of General Psychiatry, 67, 1265-1273.

doi:10.1001/archgenpsychiatry.2010.151

Miller, I.W., Keitner, G.I., Whisman, M.A., Ryan, C.E., Epstein, N.B., \& Bishop, D.S. (1992). Depressed patients with dysfunctional families: Description and course of illness. Journal of Abnormal Psychology, 101, 637-646. doi: 10.1037/0021-843X.101.4.637 
Miller, I.W., McDermut, W., Gordon, K.C., Keitner, G.I., Ryan, C.E., \& Norman, W. (2000).

Personality and family functioning in families of depressed patients. Journal of

Abnormal Psychology, 109, 539-545. doi: 10.1037/0021-843X.109.3.539

Nasreddine, Z. S., Phillips, N. A., Bedirian, V., Charbonneau, S., Whitehead, V., Collin, I., . . .

Chertkow, H. (2005). The montreal cognitive assessment, MoCA: A brief screening tool for mild cognitive impairment. Journal of the American Geriatrics Society, 53, 695-699. doi:10.1111/j.1532-5415.2005.53221.x

Okasha, A., el Akabawi, A.S., Snyder, K.S., Wilson, A.K., Youssef, I., \& el Dawla, A.S. (1994). Expressed emotion, perceived criticism, and relapse in depression: a replication in an Egyptian community. American Journal of Psychiatry, 151, 1001-1005.

Okun, M.A., \& Keith, V.M. (1998) Effects of positive and negative social exchanges with various sources on depressive symptoms in younger and older adults. Journal of Gerontology: Psychological Sciences, 53B, 4-20. doi: 10.1093/geronb/53B.1.P4

Olson, D. H., Russell, C. S., \& Sprenkle, D. H. (1983), Circumplex Model of Marital and Family Systems: V1. Theoretical Update. Family Process, 22, 69-83.

doi: 10.1111/j.15455300.1983.00069.x

Penninx, B. W., Geerlings, S. W., Deeg, D. J., van Eijk, J. T., van Tilburg, W., \& Beekman, A. T. (1999). Minor and major depression and the risk of death in older persons. Archives of General Psychiatry, 56, 889-895.

Pinquart, M., Duberstein, P. R., \& Lyness, J. M. (2006). Treatments for later-life depressive conditions: A meta-analytic comparison of pharmacotherapy and psychotherapy. The American Journal of Psychiatry, 163, 1493-1501. doi:10.1176/appi.ajp.163.9.1493 
Procidano, M. E., \& Heller, K. (1983). Measures of perceived social support from friends and from family: Three validation studies. American Journal of Community Psychology, 11, $1-24$.

Reynolds, C.F. III, Frank, E., Perel, J.M., Imber, S.D., Cornes, C., Miller, M.D., ... Kupfer, D.J. (1999b). Nortriptyline and interpersonal psychotherapy as maintenance therapies for recurrent major depression: a randomized controlled trial in patients older than 59 years. Journal of the American Medical Association, 281, 39-45.

Reynolds, C.F. III, Miller, M.D., Pasternak, R.E., Frank, E., Perel, J.M., Cornes, C., ...Kupfer, D.J. (1999b). Treatment of bereavement-related major depressive episode in later life: a controlled study of acute and continuation treatment with nortriptyline and interpersonal psychotherapy. American Journal of Psychiatry, 156, 202-208.

Rook, K.S. (1984). The negative side of social interaction: Impact on psychological well-being. Journal of Personality and Social Psychology, 46, 1097-1108. doi: 10.1037/00223514.46.5.1097

Rook, K.S. (2001). Emotional health and positive versus negative social exchanges: a daily diary analysis. Applied Developmental Science, 5, 86-97.

Russell, D. W., \& Cutrona, C. E. (1991). Social support, stress, and depressive symptoms among the elderly: Test of a process model. Psychology and Aging, 6, 190-201.

Rubin, D.B. (1987). Multiple imputation for nonresponse in surveys. New York: Wiley.

Ryff, C. D. (1989). In the eye of the beholder: Views of psychological well-being among middleaged and older adults. Psychology and Aging, 4, 195-201.

Schafer, J.L., \& Graham, J.W. (2002). Missing data: our view of the state of the art. Psychological Methods, 7, 147-177. 
Seaburn, D.B., Lyness, J.M., Eberly, S., \& King, D.A. (2005). Depression, perceived family criticism, and functional status among older, primary-care patients. American Journal of Geriatric Psychiatry, 13, 766-772.

Shields, C. G., Franks, P., Harp, J. J., Campbell, T. L., \& McDaniel, S. H. (1994). Family Emotional Involvement and Criticism Scale (FEICS): II. Reliability and validity studies. Family Systems Medicine, 12, 361-377. doi:10.1037/h0089289

Shields, C. G., Franks, P., Harp, J. J., Campbell, T. L., McDaniel, S. H., \& Cambell, T.L. (1992). A self-report scale to measure expressed emotion. Journal of Marital and Family Therapy, 18, 395-407.

Steffens, D. C., Pieper, C. F., Bosworth, H. B., MacFall, J. R., Provenzale, J. M., Payne, M. E., \& ... Krishnan, K. R. (2005). Biological and social predictors of long-term geriatric depression outcome. International Psychogeriatrics, 17(1), 41-56. doi:10.1017/S1041610205000979

Swindle, R.W., Heller, K.H., Alexander, D.B., Allen, S.M., \& Wyman, M.F. (2001). Sources of Stressor-Specific Negative Transactions and Depressive Symptoms Among White and African American Older Women. Applied Developmental Psychology, 5, 98-111.

Tabachnick, B. G., \& Fidell, L. S. (2007). Using multivariate statistics. pp. 5-7, 11-12, 27-49, 6272, \& 441-444. Boston, MA: Pearson Education, Inc.

Thompson, M. G., \& Heller, K. (1990). Facets of support related to well-being: Quantitative social isolation and perceived family support in a sample of elderly women. Psychology and Aging, 5(4), 535-544.

Uchino, B. N., Holt-Lunstad, J., Smith, T. W., \& Bloor, L. (2004). Heterogeneity in social networks: A comparison of different models linking relationships to psychological 
outcomes. Journal of Social and Clinical Psychology, 23(2), 123-139.

doi:10.1521/jscp.23.2.123.31014

Uchino, B. N., Holt-Lunstad, J., Uno, D., \& Flinders, J. B. (2001). Heterogeneity in the social networks of young and older adults: Prediction of mental health and cardiovascular reactivity during acute stress. Journal of Behavioral Medicine, 24(4), 361-382.

doi:10.1023/A:1010634902498

Uehara, T., Yokoyarna, T., Goto, M., \& Ihda, S. (1996). Expressed emotion and short-term treatment outcome of outpatients with major depression. Comprehensive Psychiatry, 37, 299-304.

Umberson, D. (1992). Relationships between adult children and their parents: Psychological consequences for both generations. Journal of Marriage \& the Family, 54(3), 664-674. doi:10.2307/353252

van Tilburg, T. (1998). Losing and gaining in old age: changes in personal network size and social support in a four-year longitudinal study. Journals of Gerontology: Social Sciences, 53B, S313-S323.

Vaughn, C.E. \& Leff J.P. (1976). The influence of family and social factors on the course of psychiatric illness. A comparison of schizophrenic and depressed neurotic patients. The British Journal of Psychiatry, 129, 125 - 137.

Vinkers, D.J., Gussekloo, J., Stek, M.L., Westendorp, R.G.J., van der Mast, R.C. (2004). Temporal relation between depression and cognitive impairment in old age: prospective population based study. British Medical Journal, 329, 881.

doi:10.1136/bmj.38216.604664.DE 
von Hippel. (2007). Regression with missing Ys: an improved strategy for analyzing multiply imputed data. Sociological Methodology, 37, 83-117.

Wallsten, S. M., Tweed, D. L., Blazer, D. G., \& George, L. K. (1999). Disability and depressive symptoms in the elderly: The effects of instrumental support and its subjective appraisal. International Journal of Aging \& Human Development, 48(2), 145-159.

Weissman, M.M. (1987). Advances in psychiatric epidemiology: rates and risks for major depression. American Journal of Public Health, 77, 445-451.

Zeiss, A.M., Lewinsohn, P.M., Rohde, P., \& Seeley, J.R. (1996). Relationship of Physical Disease and Functional Impairment to Depression in Older People. Psychology and Aging, 11, 572-581. 


\section{Appendix A \\ Patient Health Questionnaire-9 (PHQ-9)}

Instructions: Over the past two weeks, how often have you been bothered by any of the following problems?

Not at all

0

Several days
1

More than half the days

2

Nearly every day

3

1. Little interest or pleasure in doing things.

2. Feeling down, depressed, or hopeless.

3. Trouble falling or staying asleep, or sleeping too much.

4. Feeling tired or having little energy.

5. Poor appetite or overeating.

6. Feeling bad about yourself - or that you are a failure of have let yourself or your family down.

7. Trouble concentrating on things, such as reading the newspaper or watching television.

8. Moving or speaking so slowly that other people could have noticed? Or the opposite-being so fidgety or restless that you have been moving around a lot more than usual.

9. Thought you would be better off dead or of hurting yourself in some way. 


\section{Appendix B \\ Psychological Well-Being}

Instructions: Please indicate how much you are in agreement with each of the following statements by circling the number between " 1 " and " 6 " according to the response key shown below.

$\begin{array}{cccccc}\begin{array}{c}\text { Strongly } \\ \text { disagree }\end{array} & \text { Disagree } & \begin{array}{l}\text { Slightly } \\ \text { disagree }\end{array} & \begin{array}{l}\text { Slightly } \\ \text { agree }\end{array} & \text { Agree } & \begin{array}{c}\text { Strongly } \\ \text { agree }\end{array} \\ 1 & 2 & 3 & 4 & 5 & 6\end{array}$

\section{Autonomy Items}

My decisions are not usually influenced by what everyone else is doing.

I have confidence in my opinions even if they are contrary to the general consensus.

I have confid ence in my own opinions, even if they are different from the way most other people think.

I tend to worry about what other people think of me.

I often change my mind about decisions if my friends or family disagree.

I am not afraid to voice my opinions, even when they are in opposition to the opinions of most people.

Being happy with myself is more important to me than having others approve of me.

It's difficult for me to voice my opinions on controversial matters.

I tend to be influenced by people with strong opinions.

I judge myself by what I think is important, not by what others think is important.

I judge myself by what I think is important, not by the values of what others think is important.

\section{Environmental Mastery}

I am good at juggling my time so that I can fit everything in that needs to get done.

I often feel overwhelmed by my responsibilities.

I am quite good at managing the many responsibilities of my daily life.

I am good at managing the responsibilities of daily life.

I do not fit very well with the people and community around me.

I have difficulty arranging my life in a way that is satisfying to me.

I have been able to create a lifestyle for myself that is much to my liking.

I generally do a good job of taking care of my personal finances and affairs.

In general, I feel I am in charge of the situation in which I live.

The demands of everyday life often get me down.

\section{Personal Growth}

I am not interested in activities that will expand my horizons.

I have the sense that I have developed a lot as a person over time.

When I think about it, I haven't really improved much as a person over the years.

I think it is important to have new experiences that challenge how I think about myself and the world. 
I think it is important to have new experiences that challenge how you think about yourself and the world.

I don't want to try new ways of doing things -- my life is fine the way it is.

I do not enjoy being in new situations that require me to change my old familiar ways of doing things.

There is truth to the saying you can't teach an old dog new tricks.

For me, life has been a continuous process of learning, changing, and growing.

For me, life has been a continuous process of learning, changing, and growth.

I gave up trying to make big improvements or changes in my life a long time ago.

\section{Positive Relations}

I don't have many people who want to listen when I need to talk.

I enjoy personal and mutual conversations with family members and friends.

I often feel lonely because I have few close friends with whom to share my concerns.

It seems to me that most other people have more friends than I do.

People would describe me as a giving person, willing to share my time with others.

Most people see me as loving and affectionate.

I know I can trust my friends, and they know they can trust me.

Maintaining close relationships has been difficult and frustrating for me.

I have not experienced many warm and trusting relationships with others.

\section{Purpose in Life}

I enjoy making plans for the future and working to make them a reality.

My daily activities often seem trivial and unimportant to me.

I am an active person in carrying out the plans I set for myself.

I tend to focus on the present, because the future nearly always brings me problems.

I don't have a good sense of what it is I'm trying to accomplish in life.

I sometimes feel as if I have done all there is to do in life.

I sometimes feel as if I've done all there is to do in life.

I used to set goals for myself, but that now seems like a waste of time.

Some people wander aimlessly through life but I am not one of them.

I live life one day at a time and don't really think about the future.

\section{Self-Acceptance}

I feel like many of the people I know have gotten more out of life than I have.

In general, I feel confident and positive about myself.

When I compare myself to friends and acquaintances, it makes me feel good about who I am. My attitude about myself is probably not as positive as most people feel about themselves.

I made some mistakes in the past, but I feel that all in all everything has worked out for the best.

The past had its ups and downs, but in general, I wouldn't want to change it.

In many ways, I feel disappointed about my achievements in life.

When I look at the story of my life, I am pleased with how things have turned out.

When I look at the story of my life, I am pleased about how things have turned out.

When I look at the story of my life, I am pleased with how things have turned out so far. I like most parts of my personality. 
I like most aspects of my personality. 


\section{Appendix C}

\section{Modified Family Emotional Involvement and Criticism Scale (Modified FEICS)}

Instructions: Please circle the number that shows how much you agree or disagree with each of the following statements about your relationship with your family.

$\begin{array}{ccccc}\begin{array}{l}\text { Almost } \\ \text { never }\end{array} & \begin{array}{l}\text { Once } \\ \text { in a } \\ \text { while }\end{array} & \text { Sometimes } & \text { Often } & \begin{array}{c}\text { Almost } \\ \text { always }\end{array} \\ 1 & 2 & 3 & 4 & 5\end{array}$

1. My family approves of the way I live my life (PC) Reversed

2. My family thinks I should be more active (PC).

3. My family doesn't like the way I take of myself (PC).

4. When there are concerns or difficulties in our relationship, we don't talk about them

(EI).Reversed

5. My family doesn't like how I handle money (PC).

6. If I start talking about my concerns, my family changes the subject (EI). Reversed

7. My family tries to get me to change (PC).

8. My family rarely asks me about problems I have (EI). Reversed

9. My family approves of the things I do (PC)

10. My family talks with me about my health (EI)

11. My family encourages me to talk about my worries (EI)

12. My family is attentive to the problems I have (EI) 


\section{Appendix D}

\section{Perceived Social Support-Family Subscale}

Directions: The statements which follow refer to feelings and experiences which occur to most people at one time or another in their relationships with their families. For each statement there are three possible answers: Yes, No, Don't know. Please circle the answer you choose for each item.

Yes No Don't know 1. My family gives me the moral support I need.

Yes No Don't know 2. I get good ideas about how to do things or make things form my family. Yes No Don't know 3. Most other people are closer to their family than I am.

Yes No Don't know 4. When I confide in the members of my family who are closest to me, I get the idea that it makes them uncomfortable.

Yes No Don't know 5. My family enjoys hearing about what I think.

Yes No Don't know 6. Members of my family share many of my interests.

Yes No Don't know 7. Certain members of my family come to me when they have problems or need advice.

Yes No Don't know 8. I rely on my family for emotional support.

Yes No Don't know 9. There is a member of my family I could go to if I were just feeling down, without feeling funny about it later.

Yes No Don't know 10. My family and I are very open about what we think about things.

Yes No Don't know 11. My family is sensitive to my personal needs.

Yes No Don't know 12. Members of my family come to me for emotional support.

Yes No Don't know 13. Members of my family are good at helping me solve problems.

Yes No Don't know 14. I have a deep sharing relationship with a number of members of my family.

Yes No Don't know 15. Members of my family get good ideas about how to do things or make things from me.

Yes No Don't know 16. When I confide in members of my family, it makes me uncomfortable. Yes No Don't know 17. Members of my family seek me out for companionship.

Yes No Don't know 18. I think that my family feels that I'm good at helping them solve problems.

Yes No Don't know 19. I don't have a relationship with a member of my family that is as close as other people's relationships with family members.

Yes No Don't know 20. I wish my family were much different. 


\section{Appendix E}

\section{Montreal Cognitive Assessment (MOCA)}

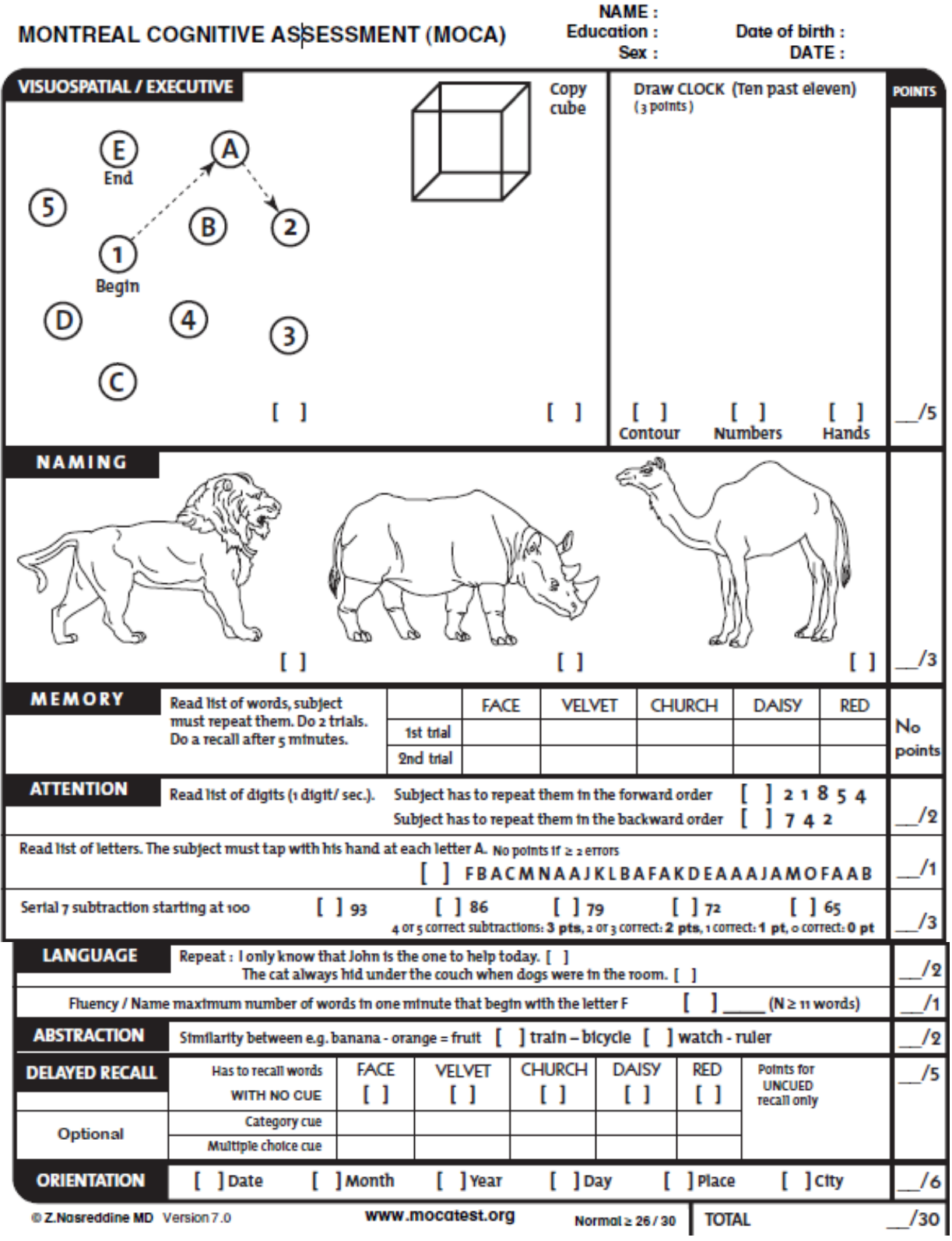


Figure 1

Recruitment Summary

$$
\mathrm{N}=\mathbf{5 4 3}
$$

\section{Received study invitation}
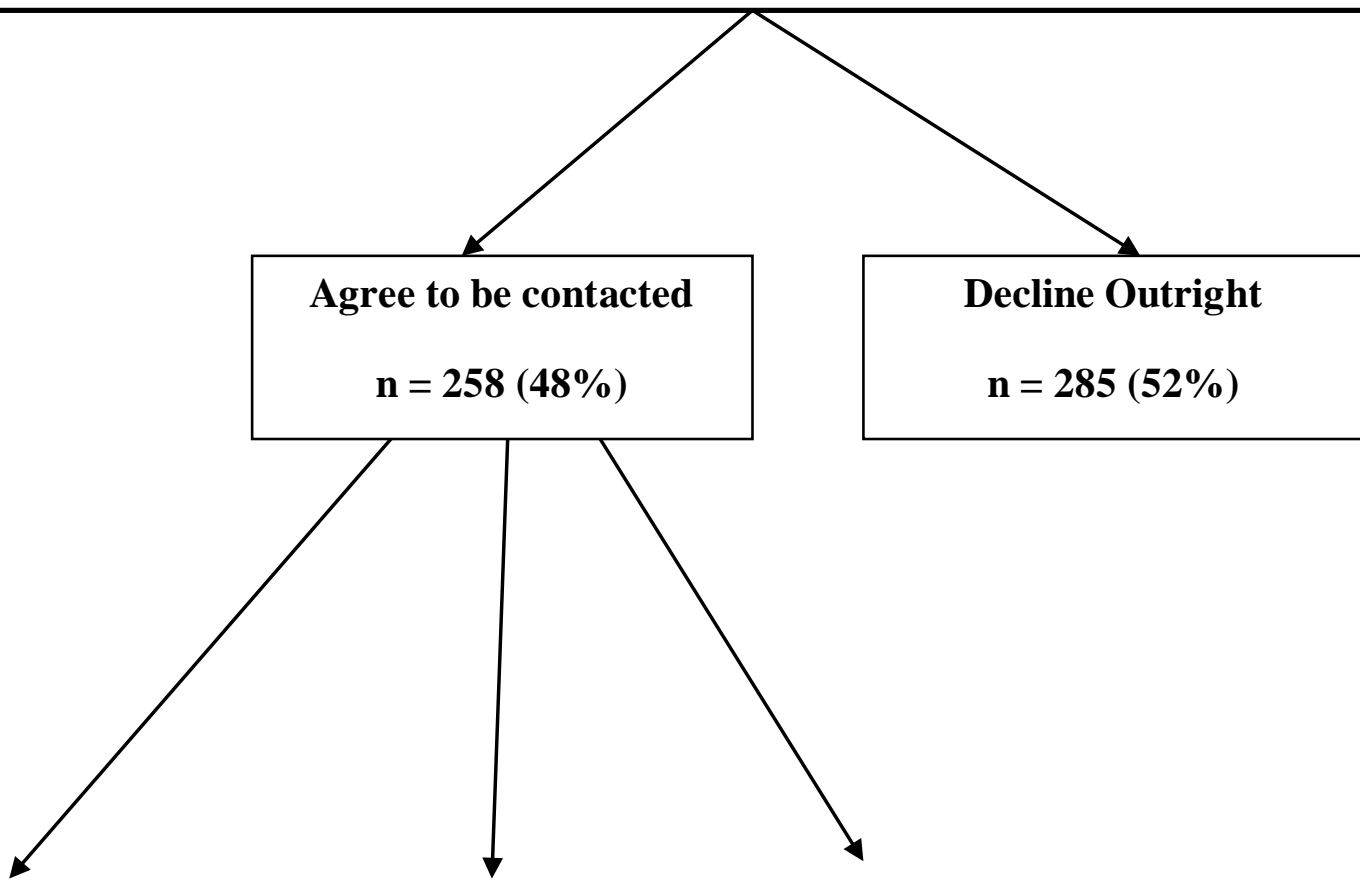

\section{Declined-phone} contact

\begin{tabular}{|c|}
\hline Ineligible \\
$\mathbf{n}=72(28 \%)$ \\
\hline
\end{tabular}

\begin{tabular}{|c|}
\hline Enrolled \\
$\mathrm{N}=114(44 \%)$ \\
\hline
\end{tabular}




\section{Tables}

Table 1

Demographics of Sample

\begin{tabular}{|c|c|c|c|c|c|}
\hline & $n$ & Frequency & Valid Percent & $M$ & $S D$ \\
\hline Age (years) & 113 & & & 69.9 & 8.7 \\
\hline Gender & 113 & & & & \\
\hline Male & & 46 & 40.7 & & \\
\hline Female & & 67 & 59.3 & & \\
\hline Race & 110 & & & & \\
\hline White & & 90 & 81.8 & & \\
\hline African American & & 15 & 13.7 & & \\
\hline Hispanic/Latino & & 3 & 2.7 & & \\
\hline Mixed race & & 2 & 1.8 & & \\
\hline Education (years) & 109 & & & 13.7 & 2.9 \\
\hline Marital status & 111 & & & & \\
\hline Single & & 9 & 8.1 & & \\
\hline Married & & 51 & 46.0 & & \\
\hline Legally separated & & 7 & 6.3 & & \\
\hline Divorced & & 23 & 20.7 & & \\
\hline Widowed & & 21 & 18.9 & & \\
\hline Living arrangement & 109 & & & & \\
\hline Alone & & 48 & 44.0 & & \\
\hline With spouse/sig. other & & 37 & 34.0 & & \\
\hline With spouse/sig. other & & 12 & 11.0 & & \\
\hline and children & & 5 & 4.6 & & \\
\hline With other family & & 5 & 4.6 & & \\
\hline Other & & 2 & 1.8 & & \\
\hline
\end{tabular}


Table 2

Primary diagnosis

\begin{tabular}{ll}
\hline & $\mathrm{N}(\%)$ \\
Mood Disorder & $\mathbf{9 4}(\mathbf{8 2 . 5 \% )}$ \\
Major Depressive Disorder & $54(48.2)$ \\
Dysthymia & $3(2.6)$ \\
Depressive Disorder NOS & $20(17.5)$ \\
Bipolar Disorder & $15(13.2)$ \\
Mood Disorder NOS & $2(1.8)$ \\
Anxiety Disorder & $\mathbf{1 0}(\mathbf{8 . 7})$ \\
Generalized Anxiety Disorder & $2(1.8)$ \\
Post-Traumatic Stress Disorder & $4(3.5)$ \\
Anxiety Disorder NOS & $4(3.5)$ \\
Adjustment Disorder & $\mathbf{8}(\mathbf{7 . 0})$ \\
w/Depressed Mood & $5(4.4)$ \\
w/ Mixed Anxiety and Depressed Mood. & $2(1.8)$ \\
Unspecified & $1(.9)$ \\
Total & $\mathbf{1 1 2 ( 9 8 . 2 )}$ \\
\hline
\end{tabular}

Note. 2 participants are missing primary diagnosis (1.8\%).

Table 3

Percentage Indication \% Of Participants Who Had One Or More Items Missing On Each Scale

\begin{tabular}{|c|c|c|}
\hline \multirow[b]{2}{*}{ Variable } & Time 1 & \multirow[b]{2}{*}{ Method of Measuremen } \\
\hline & Percentage of Data Missing & \\
\hline $\mathrm{PC}$ & 24.6 & Mail-in \\
\hline EI & 25.4 & Mail-in \\
\hline $\mathrm{N}$ & 18.4 & Mail-in \\
\hline $\mathrm{C}$ & 21.1 & Mail-in \\
\hline PSS-fa & 39.5 & Mail-in \\
\hline MOCA & 3.5 & In-person \\
\hline PHQ9 & .9 & In-person \\
\hline \multirow[t]{2}{*}{ PWB } & 39.5 & Mail-in \\
\hline & Time 2 & \\
\hline PHQ9 & 36.0 & In-person \\
\hline PWB & 66.7 & Mail-in \\
\hline
\end{tabular}

Note. PC = Modified Family Emotional Involvement Scale- Perceived Criticism; $\mathrm{EI}=$ Modified Family Emotional Involvement Scale-Emotional Involvement; $\mathrm{N}=$ NEO Five Factor Inventory-Neuroticism Domain; C = NEO Five Factor Inventory-Conscientiousness Domain; PSS-fa = Perceived Social Support-Family; MOCA = Montreal Cognitive Assessment; PHQ9 = Patient Health Questionnaire9; PWB = Ryff's Psychological Well-Being. 
Table 4

Descriptive statistics for study variables

\begin{tabular}{lccccc} 
Variables & $n$ & $M$ & $S D$ & Range & $\alpha$ \\
PC & 86 & 15.7 & 4.6 & $6-25$ & .70 \\
EI & 85 & 18.8 & 5.3 & $6-30$ & .84 \\
N t-score & 93 & 57.6 & 10.0 & $36-75$ & .83 \\
C t-Score & 94 & 43.4 & 11.5 & $25-73$ & .84 \\
MOCA & 110 & 22.6 & 4.4 & $9-29$ & -- \\
PSS-fa & 77 & 10.6 & 6.5 & $0-20$ & .93 \\
PHQ9 Time 1 & 113 & 9.2 & 6.2 & $0-24$ & .82 \\
PHQ9 Time 2 & 73 & 7.5 & 5.3 & $0-24$ & .81 \\
PWB Time 1 & 69 & 82.8 & 14.3 & $53-113$ & .87 \\
PWB Time 2 & 38 & 83.0 & 14.4 & $44-105$ & .89 \\
\hline
\end{tabular}

Note. Descriptives were calculated prior to imputation.

$\mathrm{PC}=$ Modified Family Emotional Involvement Scale- Perceived Criticism; EI =

Modified Family Emotional Involvement Scale-Emotional Involvement; $\mathrm{N}=\mathrm{NEO}$

Five Factor Inventory-Neuroticism Domain; C = NEO Five Factor Inventory-

Conscientiousness Domain; PSS-fa = Perceived Social Support-Family; MOCA = Montreal Cognitive Assessment; PHQ-9 = Patient Health Questionnaire-9; PWB = Ryff’s Psychological Well-Being 
Table 5

Pooled Correlation Coefficients of Study Variables

\begin{tabular}{|c|c|c|c|c|c|c|c|c|c|c|c|c|}
\hline Variable & Age & $\begin{array}{l}\text { Educ } \\
\text { (years) }\end{array}$ & $\mathrm{PC}$ & EI & $\mathrm{N}$ & $\mathrm{C}$ & PSS-fa & Moca & $\begin{array}{l}\text { PHQ-9 } \\
\text { T1 }\end{array}$ & $\begin{array}{l}\text { PWB } \\
\text { T1 }\end{array}$ & $\begin{array}{l}\text { PHQ-9 } \\
\text { T2 }\end{array}$ & $\begin{array}{l}\text { PWB } \\
\mathrm{T} 2\end{array}$ \\
\hline Age & - & .05 & -.17 & .18 & -.18 & .20 & .20 & $-.23 *$ & $-.29 * *$ & -.17 & -.20 & .10 \\
\hline $\begin{array}{l}\text { Educ } \\
\text { (years) }\end{array}$ & & - & .05 & -.05 & -.08 & -.11 & -.12 & $.36 * * *$ & -.08 & .11 & -.14 & .14 \\
\hline $\mathrm{PC}$ & & & - & $-.49 * * *$ & $.32 * *$ & $-.42 * * *$ & $-.25 *$ & .08 & $.31 * *$ & $-.38 * * *$ & .20 & $-.35 * * *$ \\
\hline EI & & & & - & $-.30 * *$ & .07 & $.55^{* * * *}$ & -.11 & -.20 & $.28 *$ & -.17 & .21 \\
\hline $\mathrm{N}$ & & & & & - & $-.33 * * *$ & -.24 & .11 & $.47 * * *$ & $-.60 * * *$ & $.43 * *$ & $-.39 * *$ \\
\hline $\mathrm{C}$ & & & & & & - & .04 & -.10 & $-.41 * * *$ & $.31 *$ & $-.48 *$ & .22 \\
\hline PSS-fa & & & & & & & - & $-.24 *$ & $-.28 *$ & .18 & -.12 & .28 \\
\hline Moca & & & & & & & & - & .08 & .02 & -.20 & .04 \\
\hline PHQ9 T1 & & & & & & & & & - & $-.44 *$ & $.57 * * *$ & $-.29 *$ \\
\hline PWB T1 & & & & & & & & & & - & $-.36 * *$ & $.72 * *$ \\
\hline PHQ9 T2 & & & & & & & & & & & - & $-.28 *$ \\
\hline PWB T2 & & & & & & & & & & & & - \\
\hline
\end{tabular}

Note. $* p<.05, * * p<.01, * * * p<.001$.

$\mathrm{PC}=$ Modified Family Emotional Involvement Scale- Perceived Criticism; EI = Modified Family Emotional Involvement ScaleEmotional Involvement; N = NEO Five Factor Inventory-Neuroticism Domain; C = NEO Five Factor Inventory-Conscientiousness Domain; PSS-fa = Perceived Social Support-Family; MOCA = Montreal Cognitive Assessment; PHQ-9 = Patient Health Questionnaire-9; PWB = Ryff's Psychological Well-Being 
Table 6

Pooled Linear Regression Examining

whether $P C$ predicts $P H Q-9$ at Time 1, after

Controlling for Age

\begin{tabular}{|c|c|c|}
\hline Data Set & Estimated Statistic & $\mathrm{PC}$ \\
\hline \multicolumn{3}{|l|}{$\begin{array}{l}\text { Listwise } \\
n=84\end{array}$} \\
\hline & $B$ & $.35 * *$ \\
\hline & SE & .13 \\
\hline & $\mathrm{R}^{2}$ change & .07 \\
\hline \multicolumn{3}{|l|}{$\begin{array}{l}\text { Imputed } \\
N=114\end{array}$} \\
\hline \multirow[t]{3}{*}{1} & $B$ & $.29 *$ \\
\hline & SE & .12 \\
\hline & $\mathrm{R}^{2}$ change & .05 \\
\hline \multirow[t]{3}{*}{2} & $B$ & $.33 * *$ \\
\hline & $\mathrm{SE}$ & .13 \\
\hline & $\mathrm{R}^{2}$ change & .05 \\
\hline \multirow[t]{3}{*}{3} & $B$ & .34 \\
\hline & SE & .13 \\
\hline & $\mathrm{R}^{2}$ change & .06 \\
\hline \multirow[t]{3}{*}{4} & $B$ & $.33 * *$ \\
\hline & $\mathrm{SE}$ & .12 \\
\hline & $\mathrm{R}^{2}$ change & .09 \\
\hline \multirow[t]{6}{*}{5} & $B$ & $.45^{* * *}$ \\
\hline & SE & .12 \\
\hline & $\mathrm{R}^{2}$ change & .09 \\
\hline & Pooled B & $.34 *$ \\
\hline & Pooled SE & .14 \\
\hline & $\begin{array}{l}\text { Mean Avg. } \mathrm{R}^{2} \\
\text { change }\end{array}$ & .06 \\
\hline
\end{tabular}

Note. $* p<.05, * * p<.01, * * * p<.001$;

$\mathrm{PC}=$ Modified Family Emotional

Involvement Scale- Perceived Criticism; EI

$=$ Modified Family Emotional Involvement

Scale-Emotional Involvement; PHQ-9 =

Patient Health Questionnaire-9 
Table 7

Pooled Linear Regression Examining whether PC predicts $P H Q-9$ at Time 2, after Controlling for Age and PHQ-9 at Time 1

\begin{tabular}{|c|c|c|}
\hline Data Set & Estimated Statistic & $\mathrm{PC}$ \\
\hline \multirow{3}{*}{$\begin{array}{l}\text { Listwise } \\
n=58\end{array}$} & $\mathrm{~B}$ & .08 \\
\hline & SE & .12 \\
\hline & $\mathrm{R}^{2}$ change & .005 \\
\hline \multirow{2}{*}{\multicolumn{3}{|c|}{$\begin{array}{l}\text { Imputed } \\
N=114\end{array}$}} \\
\hline & & \\
\hline \multirow[t]{3}{*}{1} & B & .13 \\
\hline & SE & .10 \\
\hline & $\mathrm{R}^{2}$ change & .01 \\
\hline \multirow[t]{3}{*}{2} & B & -.14 \\
\hline & SE & .10 \\
\hline & $\mathrm{R}^{2}$ change & .01 \\
\hline \multirow[t]{3}{*}{3} & B & .11 \\
\hline & SE & .10 \\
\hline & $\mathrm{R}^{2}$ change & .01 \\
\hline \multirow[t]{3}{*}{4} & $\mathrm{~B}$ & .14 \\
\hline & SE & .10 \\
\hline & $\mathrm{R}^{2}$ change & .02 \\
\hline \multirow[t]{6}{*}{5} & B & .03 \\
\hline & SE & .11 \\
\hline & $\mathrm{R}^{2}$ change & .01 \\
\hline & Pooled B & .05 \\
\hline & Pooled SE & .16 \\
\hline & $\begin{array}{l}\text { Mean Avg. } R^{2} \\
\text { change }\end{array}$ & .04 \\
\hline
\end{tabular}

Note. Regression coefficients are nonsignificant in all model;

$\mathrm{PC}=$ Modified Family Emotional Involvement Scale- Perceived Criticism; PHQ-9 = Patient Health Questionnaire-9 
Table 8

Pooled Linear Regression Examining whether PC predicts $P W B$ at Time 1

\begin{tabular}{|c|c|c|}
\hline Data Set & Estimated Statistic & $\mathrm{PC}$ \\
\hline Listwise & $B$ & $-1.37 * * *$ \\
\hline$n=67$ & SE & 30 \\
\hline & $\mathrm{SE}$ & .38 \\
\hline \multirow{3}{*}{\multicolumn{3}{|c|}{$\begin{array}{l}\text { Imputed } \\
N=114\end{array}$}} \\
\hline & & \\
\hline & & \\
\hline \multirow[t]{3}{*}{1} & $B$ & $-1.04 * *$ \\
\hline & SE & .30 \\
\hline & $\mathrm{R}^{2}$ change & .10 \\
\hline \multirow[t]{3}{*}{2} & $B$ & -1.02 \\
\hline & SE & .30 \\
\hline & $\mathrm{R}^{2}$ change & .09 \\
\hline \multirow[t]{3}{*}{3} & $B$ & $-1.35 * *$ \\
\hline & SE & .30 \\
\hline & $\mathrm{R}^{2}$ change & .15 \\
\hline \multirow[t]{3}{*}{4} & $B$ & $-1.13 *$ \\
\hline & SE & .28 \\
\hline & $\mathrm{R}^{2}$ change & .12 \\
\hline \multirow[t]{6}{*}{5} & $B$ & $-1.60 * *$ \\
\hline & SE & .27 \\
\hline & $\mathrm{R}^{2}$ change & .24 \\
\hline & Pooled B & $-1.23 *$ \\
\hline & Pooled SE & .40 \\
\hline & $\begin{array}{l}\text { Mean Avg. } R^{2} \\
\text { change }\end{array}$ & .14 \\
\hline
\end{tabular}

Note. $* p<.01, * * p<.001$;

$\mathrm{PC}=$ Modified Family Emotional

Involvement Scale- Perceived Criticism;

PWB $=$ Ryff's Psychological Well-Being 
Table 9

Pooled Linear Regression Examining whether PC predicts $P W B$ at Time 2, after Controlling PWB at Time 1

\begin{tabular}{|c|c|c|}
\hline Data Set & Estimated Statistic & $\mathrm{PC}$ \\
\hline \multirow{2}{*}{$\begin{array}{l}\text { Listwise } \\
n=31\end{array}$} & B & -.31 \\
\hline & $\begin{array}{l}\mathrm{SE} \\
\mathrm{R}^{2} \text { change }\end{array}$ & $\begin{array}{l}.35 \\
.006\end{array}$ \\
\hline \multicolumn{3}{|l|}{$\begin{array}{l}\text { Imputed } \\
N=114\end{array}$} \\
\hline \multirow[t]{3}{*}{1} & B & $-.63 * *$ \\
\hline & $\mathrm{SE}$ & .16 \\
\hline & $\mathrm{R}^{2}$ change & .04 \\
\hline \multirow[t]{3}{*}{2} & B & .07 \\
\hline & SE & .21 \\
\hline & $\mathrm{R}^{2}$ change & .002 \\
\hline \multirow[t]{3}{*}{3} & B & -.15 \\
\hline & SE & .20 \\
\hline & $\mathrm{R}^{2}$ change & .001 \\
\hline \multirow[t]{3}{*}{4} & $\mathrm{~B}$ & $-.40 *$ \\
\hline & SE & .16 \\
\hline & $\mathrm{R}^{2}$ change & .01 \\
\hline \multirow[t]{6}{*}{5} & $\mathrm{~B}$ & $-.83 * *$ \\
\hline & $\mathrm{SE}$ & .20 \\
\hline & $\mathrm{R}^{2}$ change & .05 \\
\hline & Pooled B & -.39 \\
\hline & Pooled SE & .44 \\
\hline & Mean Avg. $\mathrm{R}^{2}$ change & .02 \\
\hline
\end{tabular}

Note. ${ }^{*} p<.05, * * p<.001$;

$\mathrm{PC}=$ Modified Family Emotional Involvement Scale-

Perceived Criticism; PWB = Ryff's Psychological

Well-Being 
Table 10

Pooled Linear Regression Examining whether EI predicts PHQ-9 at Time 1, after Controlling PC and PSS-fa

\begin{tabular}{|c|c|c|}
\hline Data Set & Estimated Statistic & EI \\
\hline \multirow{3}{*}{$\begin{array}{l}\text { Listwise } \\
n=61\end{array}$} & B & .10 \\
\hline & SE & .17 \\
\hline & $\mathrm{R}^{2}$ change & .005 \\
\hline \multicolumn{3}{|l|}{$\begin{array}{l}\text { Imputed } \\
N=114\end{array}$} \\
\hline \multirow[t]{3}{*}{1} & $\mathrm{~B}$ & -.02 \\
\hline & SE & .12 \\
\hline & $\mathrm{R}^{2}$ change & .0001 \\
\hline \multirow[t]{3}{*}{2} & $\mathrm{~B}$ & .13 \\
\hline & SE & .13 \\
\hline & $\mathrm{R}^{2}$ change & .008 \\
\hline \multirow[t]{3}{*}{3} & $\mathrm{~B}$ & .13 \\
\hline & SE & .13 \\
\hline & $\mathrm{R}^{2}$ change & .008 \\
\hline \multirow[t]{3}{*}{4} & $\mathrm{~B}$ & .13 \\
\hline & SE & .14 \\
\hline & $\mathrm{R}^{2}$ change & .006 \\
\hline \multirow[t]{6}{*}{5} & $\mathrm{~B}$ & .16 \\
\hline & SE & .14 \\
\hline & $\mathrm{R}^{2}$ change & .01 \\
\hline & Pooled B & .11 \\
\hline & Pooled SE & .15 \\
\hline & Mean Avg. $\mathrm{R}^{2}$ change & .007 \\
\hline
\end{tabular}

Note. Regression coefficients are nonsignificant in all models; PC = Modified Family Emotional Involvement Scale- Perceived Criticism; EI = Modified Family Emotional Involvement ScaleEmotional Involvement;PHQ-9 = Patient Health Questionnaire-9; PSS-fa = Perceived Social Supportfamily. 
Table 11

Pooled Linear Regression Examining whether EI predicts $P H Q-9$ at Time 2, after Controlling PC, PSSfa, and $P H Q-9$ at Time 1

\begin{tabular}{|c|c|c|}
\hline Data Set & Estimated Statistic & EI \\
\hline \multirow{3}{*}{$\begin{array}{l}\text { Listwise } \\
n=43\end{array}$} & B & -.04 \\
\hline & SE & .13 \\
\hline & $\mathrm{R}^{2}$ change & .002 \\
\hline \multirow{2}{*}{\multicolumn{3}{|c|}{$\begin{array}{l}\text { Imputed } \\
N=114\end{array}$}} \\
\hline & & \\
\hline \multirow[t]{3}{*}{1} & B & .01 \\
\hline & SE & .10 \\
\hline & $\mathrm{R}^{2}$ change & .001 \\
\hline \multirow[t]{3}{*}{2} & B & $-.30 *$ \\
\hline & SE & .10 \\
\hline & $\mathrm{R}^{2}$ change & .06 \\
\hline \multirow[t]{3}{*}{3} & B & $-.34 *$ \\
\hline & SE & .11 \\
\hline & $\mathrm{R}^{2}$ change & .06 \\
\hline \multirow[t]{3}{*}{4} & B & -.13 \\
\hline & SE & .10 \\
\hline & $\mathrm{R}^{2}$ change & .008 \\
\hline \multirow[t]{6}{*}{5} & B & .18 \\
\hline & SE & .11 \\
\hline & $\mathrm{R}^{2}$ change & .02 \\
\hline & Pooled B & -.12 \\
\hline & Pooled SE & .26 \\
\hline & Mean Avg. $\mathrm{R}^{2}$ change & .03 \\
\hline
\end{tabular}

Note. ${ }^{*} p<.01$

$\mathrm{PC}=$ Modified Family Emotional Involvement ScalePerceived Criticism; EI = Modified Family

Emotional Involvement Scale-Emotional Involvement; PSS-fa = Perceived Social Supportfamily; PHQ-9 = Patient Health Questionnaire-9 
Table 12

Pooled Linear Regression Examining whether EI predicts $P W B$ at Time 1, after Controlling PC and PSS-fa

\begin{tabular}{|c|c|c|}
\hline \multirow{2}{*}{$\begin{array}{l}\text { Data Set } \\
\text { Listwise } \\
n=48\end{array}$} & Estimated Statistic & EI \\
\hline & B & .40 \\
\hline & SE & .46 \\
\hline & $\mathrm{R}^{2}$ change & .01 \\
\hline \multirow{2}{*}{\multicolumn{3}{|c|}{$\begin{array}{l}\text { Imputed } \\
N=114\end{array}$}} \\
\hline & & \\
\hline \multirow[t]{3}{*}{1} & B & .13 \\
\hline & SE & .26 \\
\hline & $\mathrm{R}^{2}$ change & .002 \\
\hline \multirow[t]{3}{*}{2} & B & .76 \\
\hline & SE & .36 \\
\hline & $\mathrm{R}^{2}$ change & .03 \\
\hline \multirow[t]{3}{*}{3} & $\mathrm{~B}$ & .22 \\
\hline & SE & .36 \\
\hline & $\mathrm{R}^{2}$ change & .003 \\
\hline \multirow[t]{3}{*}{4} & $\mathrm{~B}$ & .54 \\
\hline & SE & .34 \\
\hline & $\mathrm{R}^{2}$ change & .02 \\
\hline \multirow[t]{6}{*}{5} & B & -.14 \\
\hline & SE & .36 \\
\hline & $\mathrm{R}^{2}$ change & .001 \\
\hline & Pooled B & .30 \\
\hline & Pooled SE & .51 \\
\hline & Mean Avg. $\mathrm{R}^{2}$ change & .01 \\
\hline \multicolumn{3}{|c|}{$\begin{array}{l}\text { Note. Regression coefficients are nonsignificant in all } \\
\text { models; PC = Modified Family Emotional } \\
\text { Involvement Scale- Perceived Criticism; EI = } \\
\text { Modified Family Emotional Involvement Scale- } \\
\text { Emotional Involvement; PWB = Ryff's Psychological } \\
\text { Well- PSS-fa = Perceived Social Support-family. }\end{array}$} \\
\hline
\end{tabular}


Table 13

Pooled Linear Regression Examining whether EI predicts PWB at Time 2, after Controlling PC, PSS$f a$, and $P W B$ at Time 1

\begin{tabular}{|c|c|c|}
\hline Data Set & Estimated Statistic & EI \\
\hline \multirow{3}{*}{$\begin{array}{l}\text { Listwise } \\
n=22\end{array}$} & B & $.80^{*}$ \\
\hline & SE & .37 \\
\hline & $\mathrm{R}^{2}$ change & .08 \\
\hline \multirow[t]{3}{*}{1} & B & -.07 \\
\hline & SE & .18 \\
\hline & $\mathrm{R}^{2}$ change & .0005 \\
\hline \multirow[t]{3}{*}{2} & B & -.22 \\
\hline & SE & .20 \\
\hline & $\mathrm{R}^{2}$ change & .0001 \\
\hline \multirow[t]{3}{*}{3} & B & -.22 \\
\hline & SE & .30 \\
\hline & $\mathrm{R}^{2}$ change & .004 \\
\hline \multirow[t]{3}{*}{4} & B & $-1.35 * *$ \\
\hline & SE & .23 \\
\hline & $\mathrm{R}^{2}$ change & .09 \\
\hline \multirow[t]{6}{*}{5} & B & $-.60 *$ \\
\hline & SE & .22 \\
\hline & $\mathrm{R}^{2}$ change & .02 \\
\hline & Pooled B & -.50 \\
\hline & Pooled SE & .61 \\
\hline & Mean Avg. $R^{2}$ change & .02 \\
\hline
\end{tabular}

Note. ${ }^{*} p<.05, * * p<.001$

PC $=$ Modified Family Emotional Involvement Scale-

Perceived Criticism; EI = Modified Family

Emotional Involvement Scale-Emotional

Involvement; PWB = Ryff's Psychological Well-

Being; PSS-fa = Perceived Social Support-family; 